\title{
Climate Variability and the Energetic Pathways of Evolution: The Origin of Endothermy in Mammals and Birds
}

\author{
Hans O. Pörtner \\ Alfred-Wegener-Institut für Polar- und Meeresforschung, \\ Ökophysiologie, Postfach 1201 61, D-27515 Bremerhaven, \\ Germany
}

Accepted 6/10/04

\section{ABSTRACT}

Large-scale climate oscillations in earth's history have influenced the directions of evolution, last but not least, through mass extinction events. This analysis tries to identify some unifying forces behind the course of evolution that favored an increase in organismic complexity and performance, paralleled by an increase in energy turnover, and finally led to endothermy. The analysis builds on the recent concept of oxygen-limited thermal tolerance and on the hypothesis that unifying principles exist in the temperature-dependent biochemical design of the eukaryotic cell in animals. The comparison of extant waterbreathing and air-breathing animal species from various climates provides a cause-and-effect understanding of the tradeoffs and constraints in thermal adaptation and their energetic consequences. It is hypothesized that the high costs of functional adaptation to fluctuating temperatures, especially in the cold (cold eurythermy), cause an increase in energy turnover and, at the same time, mobility and agility. These costs are associated with elevated mitochondrial capacities at minimized levels of activation enthalpies for proton leakage. Cold eurythermy is seen as a precondition for the survival of evolutionary crises elicited by repeated cooling events during extreme climate fluctuations. The costs of cold eurythermy appear as the single most important reason why metazoan evolution led to life forms with high energy turnover. They also explain why dinosaurs were able to live in subpolar climates. Finally, they give insight into the pathways, benefits, and trade-offs involved in the evolution of constant, elevated body temperature maintained by endothermy. Eurythermy, which encompasses cold tolerance, is thus hypothesized to be the "missing link" between ectothermy and endothermy. Body temperatures between $32^{\circ}$ and $42^{\circ} \mathrm{C}$ in mammals and birds then result from trade-offs

*E-mail: hpoertner@awi-bremerhaven.de.

Physiological and Biochemical Zoology 77(6):959-981. 2004. (C) 2004 by The University of Chicago. All rights reserved. 1522-2152/2004/7706-3052\$15.00 between the limiting capacities of ventilation and circulation and the evolutionary trend to maximize performance at the warm end of the thermal tolerance window.

\section{Introduction}

Evolution has generated highly complex animal life that specializes in limited temperature ranges between polar cold and the upper limits of permanent heat tolerance, currently estimated to be $45^{\circ}-47^{\circ} \mathrm{C}$ for all metazoans (Schmidt-Nielsen 1997). During adaptation to various climates, optimization of physiological and biochemical function has occurred depending on body temperatures. This is evident especially in the complex pattern of cold adaptation in Antarctic water breathers, which contrasts with the patterns found in tropical species with constantly high body temperatures and also in mammals and birds. Body temperatures in all ectotherms, including Antarctic fish and invertebrates, passively follow ambient values, whereas body temperatures in mammals and birds are maintained above ambient temperature by use of endothermy, the endogenous generation of heat, combined with endogenous temperature regulation and adequate insulation.

Key questions are how and why during metazoan evolution the heat production machinery emerged and why endotherms chose a permanent body temperature in the upper range of, and especially in the case of birds, close to, metazoan heat limits rather than at intermediate values. According to Ruben (1995, p. 72), "there is no compelling reason to regard lower body temperature as physiologically inferior or primitive." Cooper (2002) also concluded that the advantages are unclear for choosing $37^{\circ} \mathrm{C}$ in man but variable body temperatures of $32^{\circ}-$ $42^{\circ} \mathrm{C}$ between marsupials, mammals, and birds. In this context, the principal physiological reasons need to be identified that cause animals to undergo thermal specialization on evolutionary timescales. From a more general point of view, the question arises, do unifying evolutionary principles and forces exist that involve temperature and its oscillations and that shaped all metazoan evolution and finally the evolution of endothermy? Since endothermy involves high energy turnover, the potential role of temperature in the general evolutionary trend toward the generation of high energy turnover and then endothermic life forms needs to be elaborated. Such an understanding may help explain the role of energy turnover in determining and limiting temperature-dependent geographical distribution of 
ectothermic species and populations. It may also help explain similarities and differences between ectotherms and endotherms and finally explain the transition between the two.

Trade-offs and constraints in the thermal adaptation of cellular, tissue, and organismic functions become visible when ectotherms are compared that are specialized in various temperature regimes in different climates. On a global scale, the marine realm offers clearly defined thermal niches and thus an ideal basis for such comparisons. Such studies, ideally carried out in closely related species or populations of one species in a latitudinal cline, have recently contributed to an understanding of the physiological principles of thermal tolerance windows and the key mechanisms of thermal adaptation and limitation. From a wider perspective, there is evidence that such principles are similar across animal phyla (Pörtner 2001, 2002a, 2002b, 2002c).

The available physiological evidence indicates that maintaining performance and thus survival in the cold represents a more severe challenge to animal life than securing performance in the warm. This conclusion is in line with ecological and paleontological findings. In earth history, not all species were able to undergo cold adaptation to survive periods of global cooling. Huge climate oscillations, especially cooling events in earth history, likely have contributed to mass extinction events (Stanley 1987). For example, decreasing winter temperatures by about $4^{\circ} \mathrm{C}$ with summer temperatures remaining constant was associated with mass extinctions of marine invertebrates at the Eocene-Oligocene boundary (Ivany et al. 2000). Furthermore, the current decrease in biodiversity of marine macrofauna toward high Northern latitudes (Roy et al. 1998) may be due to the limited capacity of species to adapt to low but unstable temperatures.

Unifying design principles in higher animals include functional cell and tissue differentiation. Energy is produced aerobically. Body fluid circulation is used for oxygen and nutrient transport. Nervous control supports functional integration of various tissues into the whole organism. On evolutionary timescales, the accumulation of atmospheric oxygen is seen to be correlated with the wider use of aerobic metabolism and the consecutive gain in organismic complexity. Eukaryotes evolved when oxygen levels were close to $1 \%$ of current levels; multicellular organisms arose when oxygen increased beyond $7 \%$ (Cloud 1988). Rapid metazoan radiation set in at the end of complete global glaciation (Hoffman et al. 1998), when oxygen levels continued to increase beyond $10 \%$ of the current level. These levels allowed organisms to grow larger and more complex due to enhanced oxygen supply, first via diffusion and then via ventilatory and circulatory mechanisms. However, enhanced organismic complexity of animals, as a precondition for an increase in performance and mobility, may have occurred at the expense of a quantum increment in thermal sensitivity (Pörtner 2002a). A simple comparison illustrates this conclusion: in general, temperatures higher than $47^{\circ} \mathrm{C}$ are tolerated only temporarily by the complex metazoans (Schmidt-Nielsen 1997), whereas more simple eukaryotes such as fungi or algae still grow at temperatures of about $55^{\circ}-60^{\circ} \mathrm{C}$ (Tansey and Brock 1972). Bacteria are even simpler and thrive continuously at temperatures higher than $90^{\circ} \mathrm{C}$.

\section{Thermal Tolerance and Metabolic Design: The Conceptual Framework}

The goal of this study is to specify unifying forces behind the course of animal evolution that may have favored an increase in organismic complexity and performance, paralleled by an increase in energy turnover, and finally, transition to endothermy in mammals and birds. Recent insight that thermal tolerance windows are set by the limited capacity of oxygen supply mechanisms, as a unifying principle across animal phyla, is important in this context (Pörtner 2001, 2002a). Where whole animal thermal tolerance windows are found on the temperature scale and how wide these windows are, is ultimately determined by temperature-dependent trade-offs in molecular and cellular design, in the design of metabolic pathways, and in individual tissue functioning. All of these integrate into the functional properties of the whole organism. The biochemical traits addressed are common properties of all eukaryotes as they relate to primary metabolism and energy-dependent functions, as well as their whole organism implications. These functions include the glycolytic pathway, mitochondrial functions such as respiratory chain and Krebs cycle, as well as interactions of membrane-bound and metabolic processes. At the organismic level, the thermal responses of such fundamental biochemical mechanisms contribute to defining performance levels, thereby modulating mode of life and behavioral traits (Pörtner 2002c). The respective molecular and cellular principles are unifying in similar ways as those relating to allometric relationships (Schmidt-Nielsen 1984; Hochachka et al. 1988) or to the energetics of exercise capacity (Lindstedt et al. 1998; Pörtner 2002b, 2002c). Overall, the respective insights are in line with the general hypothesis that ambient temperature and oxygen levels set the main border conditions of animal evolution.

Based on the unifying character of these principles, this study, with adequate precaution and as a second step, extrapolates a nontaxonomic conceptual approach. Comparisons across phyla and genera are needed to elaborate the quantum leaps in the evolution of life forms with high energy turnover and, finally, endothermy (Fig. 4). The main reasons are that the full scope of such changes and the environmental situations behind them do not become visible within individual genera. Therefore, testing the hypothesis developed in this article is difficult because the groups to be studied are extinct and all physiological studies of extant groups would be biased by their recent evolutionary history and ecology. Accordingly, the energetic pathways leading to the evolution of endothermy are not fully accessible from 
comparisons of closely related extant species. However, the ataxonomic approach applied does not neglect the existence of evolutionary constraints, meaning that the phylogenetic position and associated physiological or morphological design features and constraints of species, families, or phyla may contribute to limit the thermal adaptation capacity at the organismic (highest complexity) level. For example, high magnesium levels in the hemolymph of reptant decapod crustaceans and their effect on neuromuscular function are interpreted to limit the cold adaptation capacity of this group and to exclude it from permanently cold waters $\left(<0^{\circ} \mathrm{C}\right)$ of the Antarctic (Frederich et al. 2001). Among endotherms, for example, phylogenetic constraints may be involved in determining the body temperatures in birds versus mammals (Pörtner 2002a).

In conclusion, building on the general validity of oxygenlimited thermal tolerance for animal aerobes, an understanding of temperature-dependent trade-offs and constraints in molecular, cellular, and tissue design and in their functional capacities might reveal the unifying forces and mechanistic patterns of climate (temperature)-dependent evolution of animal life. These forces and mechanisms may have finally and repeatedly led to the evolution of endothermy. An approach such as this also supports a mechanistic understanding of optimality models used to elaborate the benefits of thermal specialists versus generalists (Gilchrist 1995) and also of the general trade-offs involved in thermal adaptation (Huey and Kingsolver 1993).

\section{Thermal Tolerance Limits and Aerobic Scope}

The concept of oxygen-limited thermal tolerance is briefly summarized and updated here from previous reviews (see Pörtner et al. 2000; Pörtner 2001, 2002a, 2002c for details and further references). According to this concept, the earliest limits of thermal tolerance are set at the highest level of organizational complexity, that is, the functional coordination of organismic components toward the larger unit. In fact, low and high ends of thermal tolerance windows are set by capacity limits of circulatory and ventilatory tissues to provide sufficient oxygen to the organism. The temperature-dependent capacities of these and other tissues are related to the capacities of underlying cellular and molecular functions. This integration is reflected in the symmorphosis principle, which was originally developed for the respiratory system of mammals (Taylor and Weibel 1981). This principle says that excess capacities of individual components contributing to the functional capacity of the whole system are avoided. Accordingly, the symmorphosis principle supports an understanding of the evolutionary trend to adjust the functional design of an animal to ambient oxygen limits. Transferring this insight to thermal physiology suggested that the overall capacity of oxygen supply and delivery (ventilation and circulation) is set to be optimal only within the window of thermal tolerance. Only within this window, adequate functional scope as set by the scope for aerobic metab- olism is available to cover extra costs such as motor activity, feeding, digestion, and growth on top of those of maintenance. Beyond the limits of long-term thermal tolerance, cold as well as heat tolerance is restricted by a progressively rising mismatch between oxygen supply and demand, which is progressively limiting aerobic scope. The respective findings in water-breathing and air-breathing ectotherms also appear applicable to mammals. For example, aerobic fitness in humans is beneficial for tolerating higher body core temperatures at exhaustion (Selkirk and McLellan 2001). In the rat, progressive circulatory failure in the cold below $20^{\circ} \mathrm{C}$ leads to progressive energy deficiency and elevated lactate levels (Jourdan et al. 1989).

These conclusions appear to conflict with others that have frequently assumed a specific role of the nervous tissue in thermal tolerance. Recent findings suggest, however, that the nervous system is not a prime component in limiting thermal tolerance, but is involved only through its functional integration into the control of circulatory and ventilatory capacities. In support of this conclusion, capacity limitations in oxygen supply become visible before nervous breakdown or coma in snails (Sokolova and Pörtner 2003). Even in one of the master examples of (mammalian) heat tolerance, the African oryx antelope (Oryx gazella), recent findings (Maloney et al. 2001; Mitchell et al. 2002) question the long-standing assumption that the carotid rete is needed to protect the brain by cooling to below body temperature. In the light of the symmorphosis principle, selective brain cooling may just balance excess heat production by the brain so that, on average, similar temperatures result in brain and body. From a more general point of view, temperature-dependent adjustments of the aerobic metabolic machinery as well as of energy-consuming functions are found in several organs, arguing against tissue-specific limitations. These adjustments rather indicate general cellular tradeoffs in setting the functional capacity of tissues and organism to the required thermal tolerance window. This interpretation is in line with the suggested whole organism sensitivity to temperature extremes set at the highest complexity levels.

In conclusion, availability of aerobic scope for performance is limited to a specific temperature window. Beyond the limits of aerobic scope, survival of thermal extremes is more and more by passive endurance. Passive survival is supported by lowering energy demands through metabolic depression and by the use of anaerobic metabolism to compensate for temperatureinduced hypoxia. Survival of extremes also includes cellular and molecular anti-stress protection by antioxidative defense or heat shock proteins. The use of the heat shock response may in fact be restricted to organisms experiencing temperature extremes (Pörtner 2002a). Recent findings by Zakhartsev et al. (2004a) emphasize that the heat shock response is likely not involved within or at the borders of the thermal window of aerobic scope of cod, Gadus morhua. The absence of the heat shock response in Antarctic notothenioid fish (Hofmann et al. 2000) also suggests that this response may be more important 
in eurytherms adapted to tolerate extremes and possibly in endotherms (King et al. 2002) and less relevant in stenotherms such as Antarctic fish.

It should be noted that various animal groups with different levels of energy turnover (e.g., birds, mammals, and reptiles) survive up to similar thermal maxima, although they display largely different functional capacities. This apparent contradiction is alleviated when it is considered that, at the same body size, oxygen demand as set by lifestyle requirements, climate, and endothermy is correlated with the efficiency of gas exchange via gill or lung on the one hand, and with circulatory capacity on the other hand. Design limits then set the maximum available body temperature. Two examples illustrate these relationships: First, the reptilian lung operates at a rather low level of efficiency. Reptiles, however, due to their lower metabolic rate, reach oxygen limits at the same or even higher temperatures than mammals and birds. Second, gas exchange efficiency is higher in the bird lung than in the mammalian lung. This phylogenetic benefit allows birds to reach higher body temperatures than mammals, despite higher metabolic rates seen, on average, in birds.

\section{Setting Widths and Locations of Thermal Windows}

Within the conceptual framework summarized here, recent comparisons of marine ectothermal animals, among them closely related species or their populations from various climates and latitudes, suggested that adaptation to (1) ambient temperature means, (2) various widths of ambient temperature windows, and especially (3) narrow versus wide thermal windows in the cold are associated with specific cellular design features and their energetic consequences (see Pörtner et al. 2000; Pörtner 2001, 2002a, 2002c for details and further references). The narrowest thermal tolerance windows are found in cold-adapted Antarctic ectotherms at low resting or standard metabolic rates (SMRs). In general, these low SMRs correlate with reduced aerobic scopes for exercise, which go hand in hand with reduced capacities of ventilation and circulation. Consequently, flexibility to respond to ambient-temperature fluctuations is reduced such that narrow windows of thermal tolerance result. In contrast, elevated SMRs are observed in cold-adapted populations of subarctic eurythermal animals. They need to tolerate large diurnal and seasonal temperature fluctuations and possess wide windows of tolerance to begin with, as well as the capacity to shift the window, that is, both upper and lower tolerance limits in accordance with seasonal temperature fluctuations. High SMRs found in cold-adapted and cold-acclimated eurytherms extend to enhanced capacities of ventilation and circulation as a precondition for widened windows of thermal tolerance, and as a consequence, they support cold-compensated metabolic scopes and activity levels.

At thermal extremes on both sides of the thermal tolerance window, shortage of organismic aerobic capacity occurs and may need to be alleviated during thermal adaptation. During adaptation or acclimation to cold, this shortage is compensated for at the cellular level by mitochondrial proliferation as well as molecular and membrane adjustments, which secure tissue function. These mechanisms have been documented predominantly in muscle and more recently in brain (of Antarctic fish; Kawall et al. 2002) and are, depending on energy demand, likely expressed to various degrees in all tissues. Muscles include those responsible for ventilation and circulation; muscular capacity adjustments within organismic performance should also involve their nervous integration. As a trade-off in cold adaptation, mitochondria may absorb a large fraction of available oxygen once at the warm end of the thermal window. This oxygen demand, as it approaches the capacity of oxygen supply and leads to a loss in aerobic scope, contributes to a reduction of upper thermal limits. The change in mitochondrial densities (and capacities) thus mirrors the unidirectional shift in upper and lower thermal limits. However, this picture is overly simplistic since the width of the thermal window may also change during thermal adaptation, on seasonal or even evolutionary timescales, leading to eurythermal and stenothermal life forms with different metabolic characteristics.

1. Metabolic Capacities and Mitochondrial Functions in ColdAdapted Stenotherms and Eurytherms. One basic insight is that for two species with the same moderate performance level, the one with the colder body temperature needs more mitochondria and/or more mitochondrial enzymes for the same aerobic and thus functional capacity. Higher than moderate performance levels, however, are not reached in the cold. Compared with other vertebrates, aerobic design in terms of mitochondrial densities appears maximized in (pelagic) stenothermal Antarctic fish. On the one hand, cellular space constraints limit mitochondrial densities (Lindstedt et al. 1998). On the other hand, high mitochondrial densities should limit the functional scope of oxygen supply by reducing the space available for contractile fibers and, thereby, for maximum muscular force per unit muscular mass.

In polar stenotherms, SMR is minimized despite maximum mitochondrial densities. The reduction in SMR is linked to minimized (ATP) synthesis capacities of mitochondria (Fig. 1; Johnston et al. 1998) and, in parallel, to minimized mitochondrial proton leakage rates (Pörtner et al. 1998, 1999; Hardewig et al. 1999). Proton leakage elicits the futile cycling of metabolic pathways and the baseline respiratory idling of mitochondria but does not involve ATP turnover. The key function of this process is seen in maintaining kinetic balance between ATP production pathways and ATP consumption capacities as a kinetic precondition for a rapid rise in energy turnover (Brand et al. 1994; Krauss et al. 2002). $\mathrm{H}^{+}$leakage thus not only reflects metabolic costs associated with mitochondrial maintenance and, finally, cold adaptation (Pörtner et al. 1998), but also the costs associated with maintaining the functional capacity of 

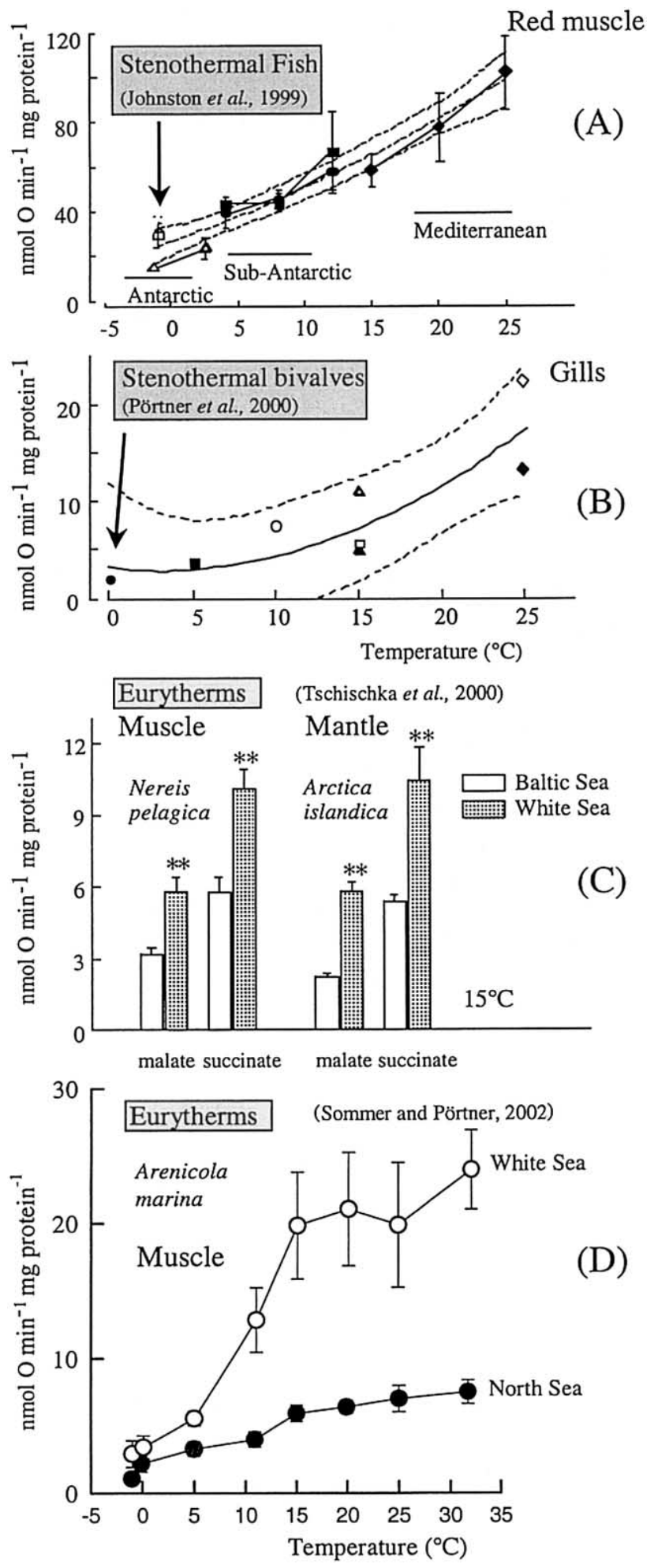

Figure 1. Mitochondrial ATP synthesis capacities (measured as state 3 respiration rates) in stenothermal and eurythermal ectotherms (modified from Pörtner et al. [2000]). A, State 3 respiration rates at various temperatures of isolated mitochondria from red musculature of Ant- tissues and their mitochondria. Mitochondrial proton leakage comprises a large fraction of SMRs; accordingly, low leakage rates and thus low SMRs indicate that Antarctic stenotherms escaped from the costs of cold tolerance. As a trade-off, however, the flexibility to enhance oxygen consumption is reduced. Maximum aerobic metabolic rates of cold-adapted stenotherms, which depend on the level of standard metabolism, remain far below those reached in warm-adapted species.

The reduction in metabolic flux in Antarctic stenotherms, despite enhanced mitochondrial densities, was suggested to be brought about by setting kinetic barriers high through a rise in activation enthalpies of key aerobic pathways and of mitochondrial proton leakage (Hardewig et al. 1999; Pörtner et al. 1999, 2000). This is only possible at constant temperature, since as a trade-off, a high activation enthalpy (i.e., a large value of $\mathrm{Q}_{10}$ ) implies a large response by the respective process to warming. For example, warming causes a large increase in baseline mitochondrial oxygen demand through largely enhanced proton leakage. A low SMR in the cold thus occurs at the expense of a rapidly rising baseline oxygen demand in the warm and a rapid loss in aerobic scope. Since capacities of ventilation and circulation are reduced at the same time in hypometabolic stenotherms, this would contribute to the low heat tolerance of Antarctic stenotherms that display the narrowest thermal windows known among animals. It thus appears that kinetic control of oxygen metabolism on the one hand, and thermal sensitivity of the intact animal on the other hand, are closely interdependent.

These principal considerations can also be applied to eurytherms in the cold, where cellular and metabolic patterns differ from those seen in the stenothermal cold (Fig. 2). In contrast to metabolic down-regulation seen in cold-adapted stenotherms, seasonal cold acclimatization and eurythermal cold adaptation to high subpolar (Northern) latitudes is associated with a compensatory increase in mitochondrial ATP-synthesis capacities (Fig. 1), proton leakage rates, and finally, organismic oxygen demand (SMR; Tschischka et al. 2000; Sommer and Pörtner 2002, 2004; T. Fischer, R. Knust, and H. O. Pörtner, unpublished data). Cold tolerance at variable temperatures is therefore associated with enhanced costs of mitochondrial

arctic (unfilled symbols), sub-Antarctic (South American, filled circles and squares), and Mediterranean fish species (filled diamonds, redrawn from Johnston et al. [1998]). B, State 3 respiration rates of mitochondria isolated from temperate and Antarctic bivalves and studied at various temperatures emphasize the down-regulation of ATP synthesis capacities, similar to fish. $C$, Elevated ATP synthesis capacities in mitochondria from White Sea compared with Baltic Sea populations of Nereis pelagica and Arctica islandica and from White Sea and North Sea populations of Arenicola marina $(D)$ correlate with elevated proton leakage rates (Tschischka et al. 2000; Sommer and Pörtner 2004). Similar patterns were observed in a comparison of North Eastern Arctic (Barents Sea) and North Sea cod (Gadus morhua) populations (T. Fischer, R. Knust, and H. O. Pörtner, unpublished data). 


\section{Eurythermal cold adaptation and performance increments go hand in hand, due to}

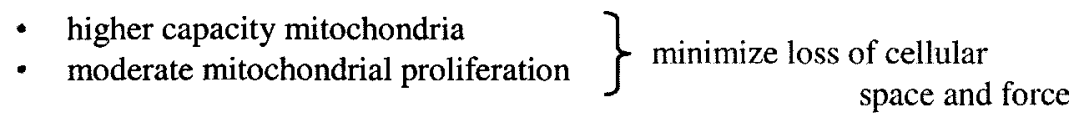

- polyunsaturated phospholipids (C20:3, 20:4, 22:6) in membranes

- higher mitochondrial proton leakage

- higher ion leakage and exchange

- higher cellular protein levels

- wider thermal tolerance windows

supporting:

- elevated standard metabolism

- enhanced aerobic scope

- enhanced levels of motor activity support high metabolic rates

minimize loss of force

allow performance shifts to

the warm

Figure 2. Similarity of cold adaptation mechanisms used in cold-adapted eurytherms and of mechanisms linked to elevated energy turnover in endotherms (extending from findings reported by van den Thillart and de Bruin [1981]; Wodtke [1981]; Hazel et al. [1992]; Hulbert and Else [1999]; Farkas et al. [2000]; Pörtner [2002a], [2002c]; Sommer and Pörtner [2002]; Zakhartsev et al. [2004b]).

maintenance and associated high oxygen demand as well as with high SMRs and, as a benefit, high functional capacity.

As a generalized conclusion, eurytherms are exposed to the full costs associated with metabolic cold adaptation. These costs may be high because they need to make use of their mitochondria within the widest possible range of short-term ambient temperature fluctuations. Accordingly, the metabolic increment elicited by rising temperature must be kept small during short-term warming to maintain aerobic scope in the warm. Proton leakage may result higher because at variable temperatures, temperature-dependent kinetic barriers such as activation enthalpies have to be set low to minimize the thermal sensitivity of oxygen demand and avoid early limitation of aerobic scope. Eurytherms may therefore choose to minimize mitochondrial densities and maximize ATP synthesis capacities instead (Fig. 1) to balance the cold-induced increase in baseline metabolic cost.

2. Membrane Functions. The cost of cold adaptation is not only associated with proton leakage across the mitochondrial membrane, but also with ion movements (leakage) across the cellular membrane, which need to be compensated for by active ion exchange mechanisms. The adaptation of mitochondrial and cellular membranes to cold modifies these passive proton and ion fluxes and, accordingly, plays a key role in defining the cost of cold adaptation. Maintenance of membrane fluidity through homeoviscous adaptation is interpreted to be a key requirement for functional integrity (Buda et al. 1994; Williams and Hazel 1994; Hazel 1995; Tiku et al. 1996) and is associated with a lower baseline level of saturated fatty acids and higher levels of monounsaturated fatty acids. Rapid oscillations in diunsaturates between nighttime coolness and afternoon heat were seen in desert teleosts and may reflect the capacity to undergo short-term thermal acclimation (Carey and Hazel 1989; Williams and Hazel 1994). However, such modifications are not clearly associated with changes in metabolic rate. The levels of polyunsaturated phospholipids (C20:3, $20: 4,22: 6$ ), especially docosahexanoic acid $(22: 6 \mathrm{n}-3)$ in cellular and mitochondrial membranes may be more relevant for setting metabolic activity. They were found to be related to metabolic rate in a comprehensive analysis of ectothermic reptiles, amphibians, and endothermic mammals (Else and Wu 1999; Hulbert and Else 1999; Hulbert et al. 2002).

The role of membranes in setting metabolic energy turnover is less clear in eurythermal versus stenothermal fish compared with other vertebrates. Compared with temperate and warm water fish, Antarctic notothenioid fishes possess largely elevated percentages and absolute levels of polyunsaturated membrane fatty acid phospholipids and, to a lesser degree, higher levels of monounsatures (Gracey et al. 1996; Storelli et al. 1998). However, this is not paralleled by enhanced leakiness for ions or high metabolic activity in Antarctic stenotherms, where in fact, metabolic activity is reduced compared with temperate and tropical fish with an active lifestyle. This apparent discrepancy is likely resolved when the densities and modulation of ion transport proteins are also considered. In fact, a down-regulation of ion channels was suggested to be key in cost reductions and to support the more sluggish mode of life of Antarctic (i.e., cold stenothermal) animals (Hochachka 1988). Otherwise, the fractional 
cost of ion regulation would increase as part of the cost of adaptation to the permanent cold (Pörtner et al. 1998).

Currently, this molecular picture and the kinetic control of transmembrane ion exchange is unclear in a comparison of eurytherms and stenotherms. Preliminary evidence shows that temperature-dependent $\mathrm{pH}$ regulation occurs at a higher cost in (cold-adapted) eurytherms than in polar stenotherms. In eurytherms, temperature-induced $\mathrm{pH}$ changes occur by active ion transport, whereas they predominantly involve the effect of passive buffering mechanisms in stenotherms (Pörtner and Sartoris 1999). These findings indicate a higher cost of ion and acid-base regulation in eurytherms than in stenotherms. As a corollary, not only the ratio and the levels of polyunsaturates over monounsaturates but also the densities and the kinetic properties of membrane proteins likely combine to set the level of temperature-dependent metabolic activity. These features would support elevated transmembrane ion exchange and leakage rates in the eurythermal cold.

3. Cellular Design Optimization for High Energy Turnover in Eurytherms. As a consequence of cost elevations elicited by wide windows of thermal tolerance, which include cold temperatures, there are benefits that result from the trade-offs involved in eurythermal cold adaptation. These benefits are associated with the enhancement of mitochondrial, cellular, and tissue functional capacities and flexibility (Fig. 2). In the eurythermal cold, kinetic barriers for ion exchange (including proton leakage) result lower than in the stenothermal cold. The functional (ATP synthesis) capacity per mitochondrium (or per mg mitochondrial protein) increases on top of increasing mitochondrial volume densities (Guderley 1998; Sommer and Pörtner 2002), likely with less mitochondrial proliferation involved than in stenotherms (Fig. 3). Accordingly, less cellular space is required for mitochondria, more can be allocated to contractile proteins, and higher cellular protein concentrations result (Zakhartsev et al. 2004b; Fig. 2). These patterns would support enhanced force development supported by aerobic metabolism. Exposure to eurythermal cold thus appears as a major driving force for enhanced metabolic capacities and maximized levels of aerobic motor activity (Pörtner 2002c). Nonetheless, eurytherms at cold temperatures still do not reach the same level of aerobic performance in the cold as their warm-acclimated conspecifics at higher temperatures. In the future, these emerging patterns need to be followed through systematically by comparing lipid compositions and densities of functional proteins as well as by the use and magnitude of kinetic barriers in membranes, preferably in closely related stenothermal and eurythermal ectotherms from various climates.

\section{Climate-Dependent Pathways of Evolution?}

The largely contrasting patterns of cold adaptation observed in Antarctic marine stenotherms versus more eurythermal
Northern hemisphere ectotherms indicate that ambient temperature fluctuations play an important role in defining energy turnover. Accordingly, obligatory links very likely exist between the stability of (cold) climates and the level of energy demand. The patterns observed in extant animals (even in genetically distinct populations of the same species) from a latitudinal cline immediately suggest that climate oscillations in the earth's history may also have played an important role in shaping the energy turnover of animals. There is indirect evidence from the marine fossil record that supports this line of thinking. The sensitivity of marine fauna to decreasing winter temperatures by about $4^{\circ} \mathrm{C}$ (with summer temperatures remaining constant) and the associated mass extinctions at the Eocene-Oligocene boundary (Ivany et al. 2000) emphasize the relevance of cold adaptation capacity. Furthermore, the current decrease in biodiversity of marine macrofauna toward high Northern latitudes (Roy et al. 1998) indicates the challenge inherent to adaptation to cold oscillating temperatures, possibly due to the obligatory increase in energy turnover and associated food demand.

A recent analysis of the marine fossil record revealed repeated stepwise increments in the fraction of mobile animals among aquatic marine ectotherms, which occurred during key mass extinction events (Fig. 4; Bambach et al. 2002). Harmful effects of aquatic $\mathrm{CO}_{2}$ accumulation or hypoxia were believed to be responsible for mass extinction events (Knoll et al. 1996; Bambach et al. 2002; Retallack et al. 2003). However, the stepwise increases in the fraction of active animals mirror transition to enhanced levels of energy expenditure. The effects of hypoxia and hypercapnia would rather hamper more active animals in the first place and, therefore, would leave these activity increments unexplained. This discrepancy is resolved in the light of the relationships between eurythermy and the level of energy turnover. Cooling events especially during Permian-Triassic and later mass extinction periods would have favored the survival of cold eurythermal life forms with high energy turnover. As outlined previously, these cold-adapted eurytherms would at the same time be highly active animals with high energy turnover (Pörtner 2002c). Such processes are effective across taxa, supporting the nontaxonomic approach adopted in this study and in Figure 4.

Moreover, the unifying principles of oxygen-limited thermal tolerance in animals leave room for the effect of any additional factor that modulates aerobic scope and thereby influences the width of the thermal tolerance window. Since both hypoxia and hypercapnia reduce aerobic scope and would thereby enhance thermal sensitivity, they may have synergistically contributed to mass extinction events, leaving only the most eurythermal animals with the largest aerobic scopes and thus activity levels behind. In addition, the degree of eurythermy increases with a reduction in body size, thereby explaining why smaller animals survived the evolutionary crises better than larger ones.

In summary, the patterns reported in Figure 4 and this anal- 


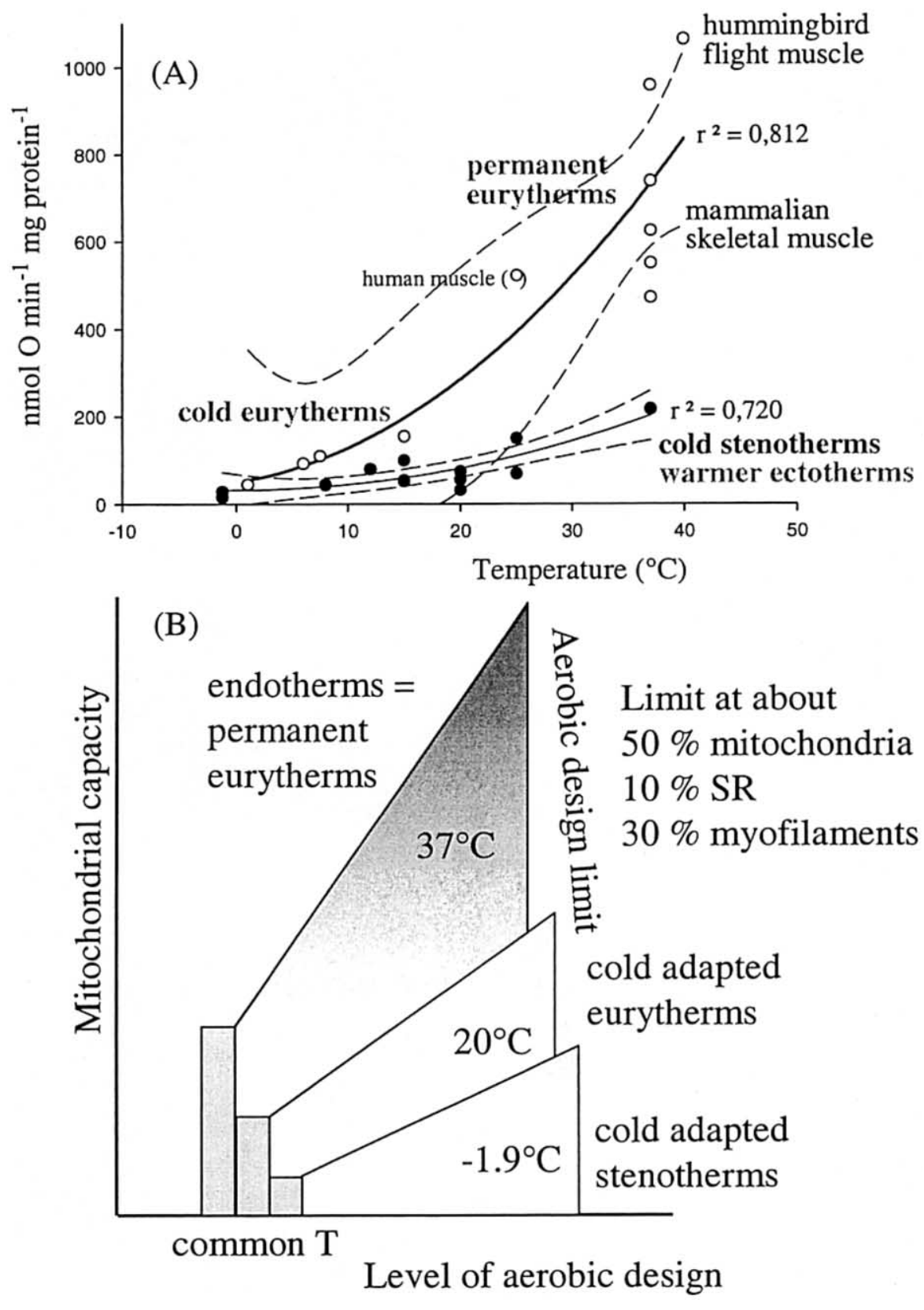

Figure 3. A, ATP synthesis capacities (state 3 respiration rates) of vertebrate (fish, amphibians, mammals, birds) ectotherm and endotherm skeletal muscle mitochondria. Data were pooled, and regressions calculated for two groups: (1) filled symbols for cold stenotherms and warmer temperate zone to tropical eurytherms, considering their lower standard metabolic rates (Fig. 6) and (2) unfilled symbols for cold-adapted eurytherms and endotherms, the latter based on similarities in cellular design in the two groups (Fig. 2). Using (cold) eurythermal mitochondria in the warm supports maximized ATP synthesis capacities. Data were obtained from the literature and recalculated, if necessary, for fish from Johnston et al. (1994), (1998); Guderley and Johnston (1996); St. Pierre et al. (1998); Blier and Lemieux (2001); for amphibians from Pye (1973); Duerr and Hillman (1993); for mammals and man from Schwerzmann et al. (1989); Hoppeler and Taylor (1992); Jackman and Willis (1996); Rasmussen and Rasmussen (2000); for hummingbirds from Suarez et al. (1991); Suarez (1992). Average $Q_{10}$ values were 2.24 for cold eurytherms and 1.74 for the stenotherms and warmer ectotherms. Dashed lines depict the $95 \%$ confidence intervals. B, Simple qualitative model of tissue design limits for aerobic metabolism and performance levels as a function of body temperature (modified after Pörtner [2002c]). In a trade-off between cellular space required by mitochondria, sarcoplasmic reticulum $(S R)$, and myofilaments, the increased capacity of mitochondrial energy production at warm temperatures allows levels of muscular power output at high body temperatures to be maximized and densities of functional components to be increased. Design limits for aerobic metabolism are reached at lower performance levels in Antarctic fish. The model takes the higher mitochondrial densities seen in Antarctic fish than in mammal and bird musculature into account (Pörtner 2002c). Furthermore, high mitochondrial densities at low capacity may characterize cold stenotherms, whereas moderate densities with high capacities may characterize cold eurytherms. 


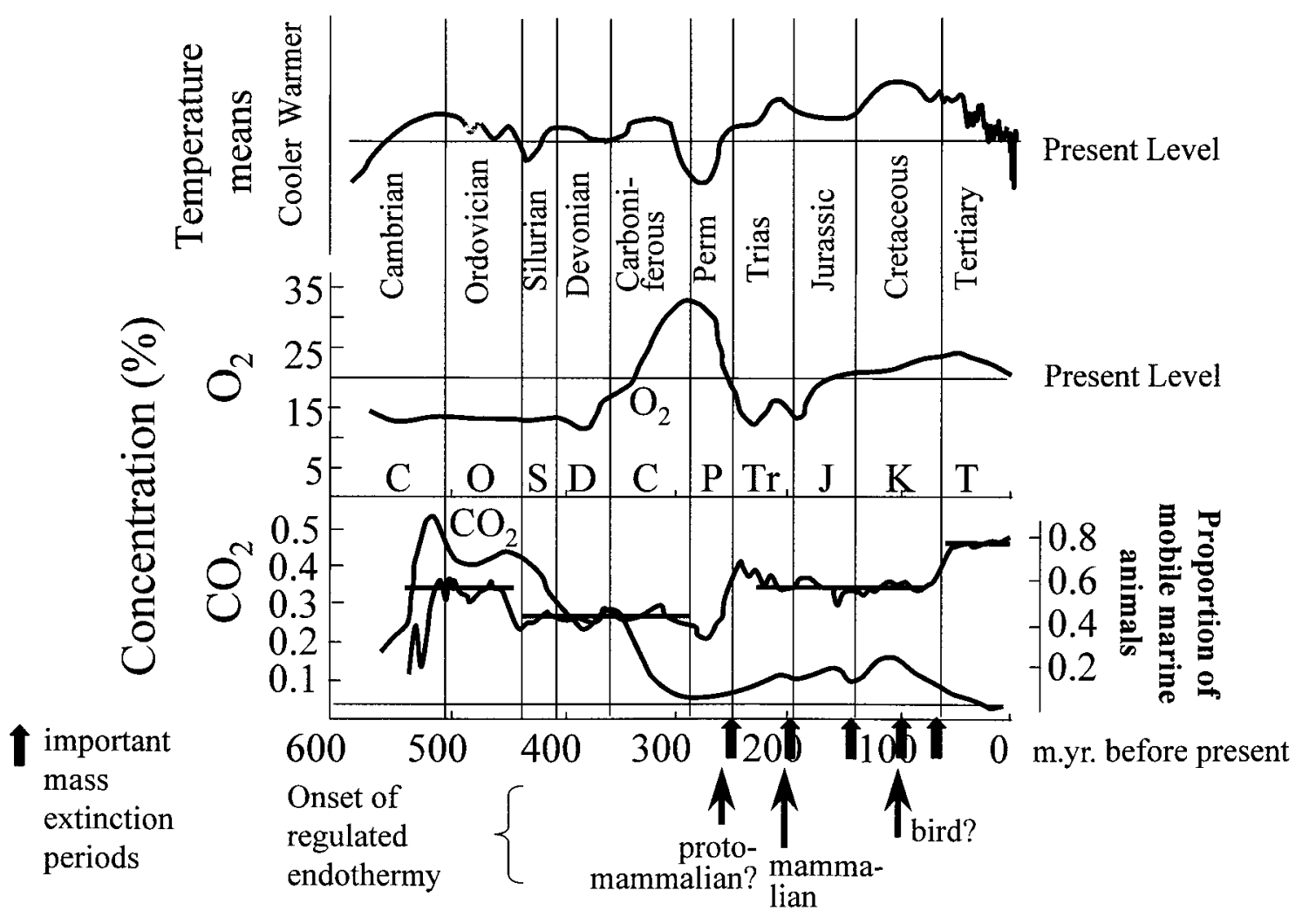

Figure 4. Correlated changes in atmospheric oxygen, $\mathrm{CO}_{2}$, and mean temperature levels compared with present atmospheric levels and the evolution of mammals and birds (modified after Dudley 1998). In the background, stepwise shifts to more mobile marine animal forms are depicted following Bambach et al. (2002). Such evolutionary shifts started with the Permian-Triassic mass extinction event, once ambient $\mathrm{O}_{2}$ levels were high and $\mathrm{CO}_{2}$ levels were low. They appear as a consequence of the survival of eurytherms during evolutionary crises associated with extreme climate oscillations. According to the "cost of eurythermy" hypothesis, progressively higher energy turnover lifestyles were favored once high-capacity circulatory and ventilatory structures had evolved. In the terrestrial realm, the earliest possible onset of protomammalian and bird endothermy is predominantly indicated by findings of respiratory turbinates in the fossil record (timescale according to Ruben 1995, 1996). The maximization of metabolic rates associated with maximized eurythermy would appear as a logical precondition for the onset of endothermy and may well have been supported by periodically elevated atmospheric oxygen levels. Progressively enhanced performance of ventilatory and circulatory systems may have been selected for during periods when atmospheric oxygen levels fell.

ysis are in line with a crucial role for cooling events and large climate oscillations in mass extinction events (Stanley 1987; Crowley and North 1988). The hypothesis arises that these climate oscillations and associated mass extinction periods may have been the primary driving forces supporting the evolution of high activity life forms in the marine realm. The question arises to what extent the same evolutionary principles hold true in terrestrial environments and may finally have contributed to the evolution of mammalian and bird endothermy.

\section{Eurythermy in Air: Implications for the Evolution of Endothermy?}

\section{Level of Eurythermy in Air}

As a precondition for the coevolution of eurythermy and life with high energy turnover, oxygen availability had to be max- imized and the capacity of oxygen supply mechanisms selected high (Fig. 2). Such preconditions were met with atmospheric oxygen levels always above a minimum of 13\%-15\% during animal evolution (Fig. 4). Moreover, such preconditions were most ideally met in terrestrial environments since breathing air rather than water implies a reduction by one order of magnitude in the energy cost of ventilation at 30-35 times higher levels of ambient oxygen and about $10^{3}$ times lower viscosity of the respiratory medium. However, new and largely different ventilatory systems had to be developed in air (lungs instead of gills in vertebrates) in most cases (except for terrestrial crabs) to exploit the excess amount of oxygen.

At the same time, thermal conductivity in air is more than 20 times less and specific heat about four times less than in water, reflecting that thermal buffering is much less in the 
terrestrial than in the aquatic environment. As a consequence, temperature changes occur on shorter timescales and at larger amplitudes in terrestrial than in aquatic environments. Therefore, terrestrial organisms at the same latitude are likely to experience much larger temperature fluctuations than aquatic organisms. Opposite to the marine realm, where temperature oscillations are less in polar and tropical than in temperate areas, those in air increase at high, especially Northern, latitudes, as estimated for mainland locations in the Americas (Gaston and Chown 1999). According to these considerations, extreme stenotherms comparable to Antarctic marine species are highly unlikely to exist in (cold) terrestrial environments. Eurytherms will predominate instead.

Nonetheless, the basic relationships between the four factors, oxygen-limited thermal tolerance, width of the thermal tolerance window, its location on the temperature scale, and metabolic capacity in relation to oxygen availability, also extend to air breathers (Pörtner 2001, 2002a). However, the reduced cost of ventilation in air may have allowed air breathers to be more eurythermal at a lower cost than water breathers, whereas thermal constraints on the circulatory system will be similar in both groups. As a consequence, if long-term heat tolerance limits in metazoa are generally found at about $45^{\circ}-47^{\circ} \mathrm{C}$, air breathers might approach that limit more closely than water breathers, provided that they have overcome the problem of desiccation stress associated with breathing air, especially at high temperatures (Chown and Gaston 1999; Cloudsley-Thompson 2001).

Despite enhanced thermal flexibility, limited thermal tolerance windows are still observed in air breathers, likely for the sake of energy savings. For example, $15^{\circ} \mathrm{C}$ is a low critical threshold for warm-adapted arthropods living in desert environments with large diurnal temperature fluctuations (cf. Pörtner $2002 a$ for review). Because these arthropods are hypometabolic, they do not undergo the cost of cold adaptation. The limited capacity of extant reptiles and amphibians to live in colder climates (Navas 2003) would also be explained by the fact that these groups are hypometabolic and lead an energysaving mode of life that disqualifies them from being active in the severe cold. However, there is evidence for metabolic cold adaptation in terrestrial ectotherms seen as an increase in SMR, for example, in insects at high, especially Northern, latitudes (Chown et al. 2002) or in cold-adapted lungless salamanders (Feder 1986). These findings suggest that an adjustment of aerobic scope is involved in thermal adaptation in air-breathing ectotherms as much as it is in water breathers (cf. Pörtner 2001, $2002 a$ for review). Such relationships may also be important in determining the trade-offs between thermal preference, thermal physiology (involving oxygen and temperature limitations), and optimal physiological performance in amphibians and reptiles in an altitudinal cline (Navas 2003). Along the same lines of thought, terrestrial zoogeography is also shaped by temperature. These relationships may also have played a role in evolutionary crises. A role for aerobic scope in the survival of
Permian-Triassic mass extinctions by therapsid vertebrates was recently suggested by Retallack et al. (2003).

These considerations cast new light on the importance of hibernation strategies in poikilothermic ectotherms or of coldinduced torpidity at night, which restrict activity to the daytime warmth (e.g., beetles, bumblebees). These strategies minimize the cost of cold adaptation that would otherwise lead to enhanced SMR if activity was to be maintained within the wide thermal window covering both daytime and nighttime temperatures on the one hand or winter temperatures on the other hand. For the same reason, amphibians and reptiles rely on the extensive use of energy-saving dormancy periods when living in seasonal climates. However, the SMRs of terrestrial animals displaying various degrees of eurythermy still need to be systematically investigated and compared in order to further support these generalized statements.

A larger degree of obligatory eurythermy in cold terrestrial than in aquatic environments suggests that terrestrial eurytherms active in the cold have available the required high level of aerobic machinery. Being eurythermal, they can make use of this machinery also for an increased level of performance in the warm. Following the predictions outlined previously, being cold-adapted in a highly oxygenated environment (air compared with water) would provide terrestrial eurytherms with the opportunity to maximize performance levels beyond those of water breathers. Despite reduced ventilation costs in air, high energetic costs of cold eurythermy would apply, supported by findings of metabolic cold adaptation, especially at high Northern latitudes.

\section{Eurythermy and Cellular Design in Endotherms}

Figures 2 and 3 indicate that there are similar trends in coldadapted eurytherms and in endotherms in terms of cellular design. Although the overall proportions of lipid monounsaturation and polyunsaturation in relation to the percent fraction of saturates in the membranes of permanent endotherms such as rat and pigeon were found as extrapolated to their permanent body temperature (Gracey et al. 1996; Farkas et al. 2000), some differences prevail compared wtih ectotherms at the same temperature. The levels of transmembrane ion transporters (Else and Hulbert 1987) of polyunsaturated phospholipids (C20:3, $20: 4,22: 6)$, especially of docosahexanoic acid (22:6n-3), are higher in cellular and mitochondrial membranes of endotherms than in those of ectotherms (Else and $\mathrm{Wu}$ 1999; Hulbert and Else 1999; Hulbert et al. 2002). Largely enhanced levels of $22: 4 n-6$ rather than of $22: 6 n-3$ fatty acids were found in brains of permanently endothermic vertebrates (mammals and birds) compared with cold water and tropical fish (Farkas et al. 2000). However, although the rates of ion exchange and proton leakage are higher in endotherms than in ectotherms and thus parallel the level of SMR, their percent contribution 
to total metabolism is the same in endotherms as in ectotherms (Brookes et al. 1998; Hulbert and Else 1999, 2000).

All of these phenomena indicate that the expression of eurythermy characters in the cold were not only involved but may even have been enhanced in the transition to endothermy. In fact, preadaptation to cold prevails especially in small mammalian hibernators that undergo extreme short-term fluctuations in body temperature during repeated short-term arousal. Short-term oscillations between $-3^{\circ}$ and $37^{\circ} \mathrm{C}$ were observed in arctic ground squirrels (Boyer and Barnes 1999). This is the largest body temperature change reported for any mammal and beyond the range found in active, warm-adapted ectotherms. The extreme changes in body temperature involved in hibernation likely rely on the permanently cold-adapted eurythermal tissue design of these mammals, which enables them to maintain baseline functions in the cold, once oxygen demand is down-regulated. The animal remains fully aerobic during these transitions (Heldmaier and Klingenspor 2000; Bock et al. 2002). Thus, oscillations between high and low body temperatures take place in the range between high pejus (getting worse) and low critical temperatures in Figure 5, with little aerobic scope left in the cold. Metabolic depression occurs in excess of the reduction in energy demand elicited by the decrease in body temperatures and likely supports the avoidance of hypoxia and of further cold adaptation costs. Body temperature minima depend on ambient temperature extremes, on the duration of the hibernation bout, and on the body size of the animals, which influences the rate of heat loss during transition to cold and in steady state. A reduction of body temperature during torpor is also found in small modern birds with some uncertainty about whether this is a late rediscovery of ancient traits or whether it represents a recent and independent evolutionary "invention" in this group (Geiser 1998).

Hibernating ground squirrels have been shown to modify (drastically enhance) the content of C18:2 fatty acids in the cold (seen in heart microsomes), with a trend to reduced percent levels of docosahexanoic acid, also seen in mitochondrial membranes (Raison et al. 1981; Lee et al. 1994; Pehowich 1994). The falling contribution of $\omega 3$ fatty acids such as docosahexanoic acid in mitochondrial membranes was paralleled by an increment in $\omega 6$ fatty acids such as arachidonic acid (Pehowich 1994). Nonetheless, separation of membrane components is seen in cold-hibernating ground squirrels, but these changes are readily reversed in the warm (Azzam et al. 2000). Despite some flexibility to undergo rapid thermal membrane adjustments, some features of permanent cold adaptation such as elevated polyunsaturate levels appear conserved in permanent endotherms compared with similar-sized (terrestrial) ectotherms at similar temperatures.

On the basis of the assumption of unifying principles of temperature-dependent cellular design, mammalian hibernators thus appear as permanent extreme eurytherms that allow body temperature to oscillate between the upper and lower end of their thermal tolerance window (Fig. 5). In a permanent eurytherm, the cold-induced maximization of aerobic capacity associated with low levels of kinetic restriction (i.e., low activation enthalpy) is not reversed during warmer periods. With enhanced capacities of ventilation and circulation, this leads to excess energy availability at warmer temperatures for a maximization of aerobic metabolic rates and scopes (Figs. 2, 3, 5).

At first sight, the adaptive flexibility with respect to body temperature fluctuations as displayed by small mammalian hibernators may have been lost in other mammals that are permanent endotherms. However, some adaptive flexibility very likely persists, a hypothesis supported by the level of tissue heterothermy found in many nonhibernating mammals. In polar mammals and birds, the ability to reduce temperature in the body or fractions thereof is extreme and implies permanent eurythermal tissue design. Peripheral temperatures are allowed to fall to below $0^{\circ} \mathrm{C}$ in extremities with the result that temperature gradients of more than $35^{\circ} \mathrm{C}$ prevail within the organism. According to recent evidence, metabolic rates may even be elevated in response to extreme tissue heterothermy (i.e., eurythermy in extremities, especially in legs). In this context, early comparisons of SMRs (i.e., basal metabolic rates) in mammals from a latitudinal cline had suggested that basal metabolism is independent of mean annual temperatures (Scholander et al. 1950). However, Lovegrove (2000) recently compared metabolic rates in mesic mammals with predictable resource availability (exemplified in rodents normalized for body size). His findings suggest that metabolic rates are higher in Nearctic (North American) and especially in Palearctic (Eurasian) species (i.e., those at high Northern latitudes) than those found in Neotropical or Afrotropical mammals. These observations are in line with the hypothesis proposed here that high costs of cold eurythermy are also expressed as the cost of tissue heterothermy in mammals. Similar relationships may prevail in birds. A recent comparison of four populations of stonechats (Wikelski et al. 2003) revealed genetically fixed elevations of metabolic rates in Northern (Austrian, Kazakhstan) populations. These were also migratory and, in general, more active than the sedentary tropical population. At high latitudes on Northern continents and at largely fluctuating ambient temperatures, the cost of heterothermy may thus play a role in maximizing metabolic expenditures and, at the same time, contribute to shape lifestyle characteristics among endotherms.

Further examples suggestive of adaptive flexibility in response to cold in all mammals and birds include cold-exposed mice, which after several generations of selection for elevated exercise levels in the cold displayed improved exercise performance and energy assimilation compared with control animals (Koteja et al. 2001). Long-term cold-acclimated pigeons displayed increased pectoralis muscle mitochondrial densities, lipid droplet accumulation, and capillary diameter, possibly with only moderate muscular shivering being involved in eliciting these processes (Mathieu-Costello et al. 1998). These re- 

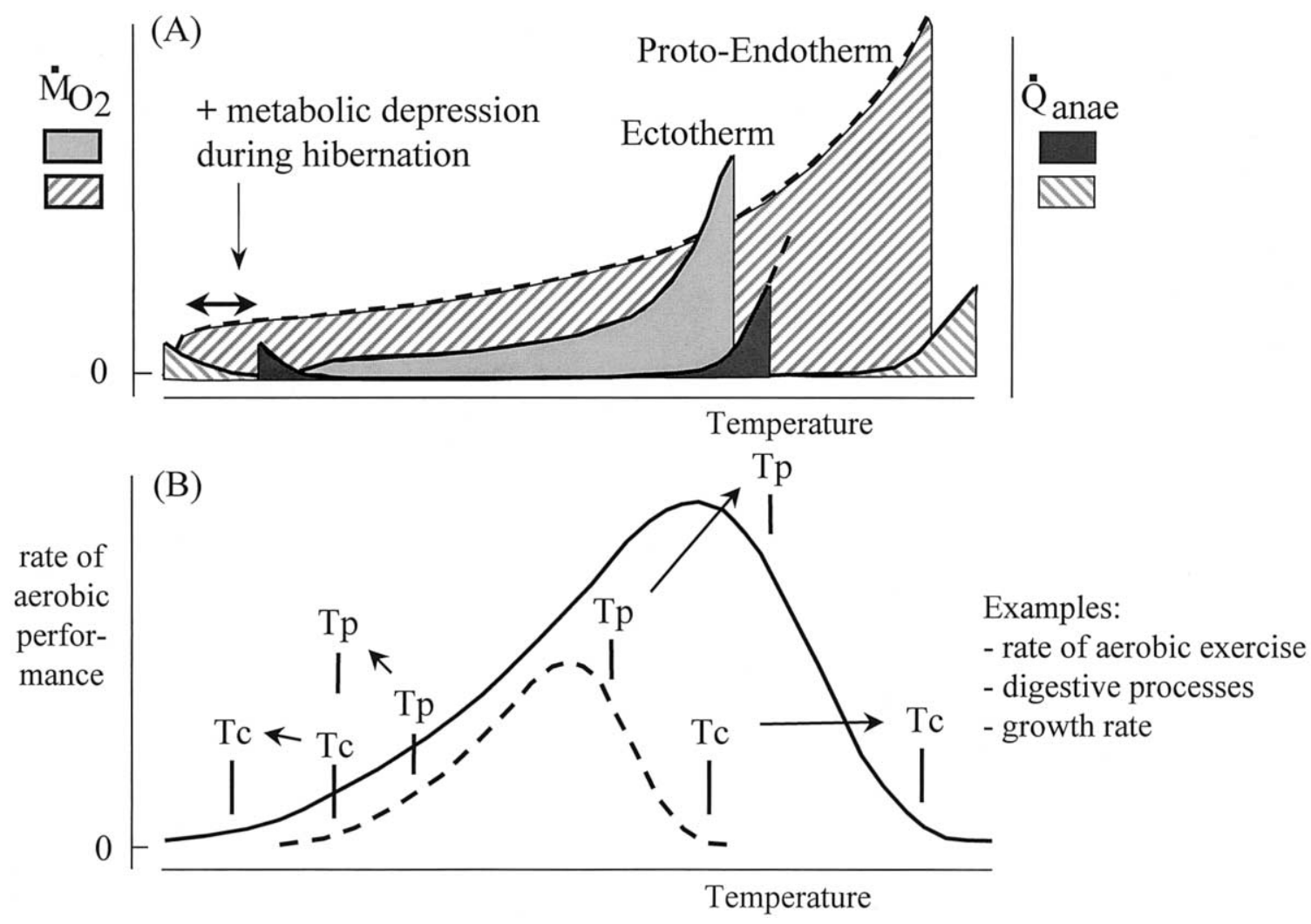

Figure 5. A, Energetic consequences of permanent eurythermal temperature adaptation. The widening of the thermal tolerance window sustained aerobically to one that includes tolerance to cold body temperatures is interpreted to cause high energetic costs. $B$, Performance curves of permanent endothermal eurytherms versus those of ectothermal eurytherms. In endotherms, maximized performance results from a permanent shift of body temperature to the upper border of the thermal tolerance window. Tp and Tc delineate pejus (=getting worse) and critical temperatures according to the thresholds of oxygen-limited thermal tolerance ( $T p=$ pejus temperature, onset of loss in aerobic scope; $T c=$ critical temperature, onset of anaerobic metabolism; terminology according to Frederich and Pörtner 2000 and Pörtner 2002a).

ports as well as the one by Wikelski et al. (2003) not only show patterns of cold adaptation in endotherms but are also in line with the general conclusion that cold adaptation and elevated exercise capacities go hand in hand because the mechanisms of metabolic adaptation to unstable cold temperatures are similar to those elicited by exercise (Pörtner 2002c).

In conclusion, enhanced exercise capacity and reactivity at high body temperatures in endotherms would result from the permanently eurythermal character of their cellular design. In other words, endotherms are permanent extreme eurytherms. This is reflected in the use of cold-adapted (eurythermal) cellular membranes with a high and noncompensated (for high temperature) capacity for ion exchange at the expense of enhanced membrane leakiness (Else and Hulbert 1987). These leaky membranes contribute to maximized oxygen turnover with the benefit of large metabolic flexibility. It needs to be emphasized here that in terms of cellular design, there is no quantum leap involved between an ectothermic and an endothermic organism, other than the maximized cellular capacity to produce and use energy in the endotherm. The ques- tion arises how the eurythermy patterns observed in extant mammals and birds arose on evolutionary timescales, a question to be addressed in the light of the fossil record and climate history.

\section{Eurythermal Ectothermy and Endothermy: An Evolutionary Continuum?}

The consistency of patterns observed in water-breathing and air-breathing ectotherms as well as in endotherms suggests that extended eurythermy and its energetic consequences are likely plesiomorphic. This principle would not only explain the evolution of life forms with high energy turnover among ectotherms, but also the transition to endothermy. This evolutionary progress results as the final energetic step that became possible in a (simplified) series from (1) being confined to relatively moderate fluctuations in water temperature, to (2) being exposed to relatively large and fast temperature fluctuations in air, to (3) using the associated increment in energy turnover to set permanent body temperature to the high end 
of the spectrum available to animal life, for the sake of maximum performance capacity.

Previously, the progressive rise in activity levels and in aerobic capacity in terrestrial tetrapods and birds has been postulated as the major process that initiated the increase in resting metabolic rate and associated heat production and finally allowed transition to endothermy (Bennett and Ruben 1979; Bennett 1991; Ruben 1995). This transition is reflected in a larger number of aerobic muscle fibers found in mammals than in extant reptiles. It is associated with about two times more voluminous internal organs (i.e., visceral organs with homeostatic function) and about two times higher aerobic capacity. The larger fraction of visceral organs is easily explained by increased demand for support, transport, and supply functions owing to elevated metabolism. In mammals compared with vertebrate ectotherms, the observed patterns of tissue design provide the basis for the, on average, fivefold to tenfold increase in resting and maximum metabolic rates and the sixfold to sevenfold increment in maximum endurable speed during exercise (Bennett and Ruben 1979; Bennett 1991; Ruben 1995). The enhanced metabolic rate is the prime source of heat required for endothermy. Brown adipose tissue is not primarily required in thermogenesis (and in fact not found in birds, marsupials, and echidnas; Grigg and Beard 2000). Heat is rather provided by muscles and viscera (Else and Hulbert 1987; Brand et al. 1991; Steen et al. 1996). Increased heat dissipation results from the net rise in (cellular membrane) ion and (mitochondrial) proton leakage rates, which are associated with elevated ion transport rates across cellular membranes and with high ATP synthesis capacities due to elevated mitochondrial capacities (Fig. 3) and densities. These processes support the increase in reactivity and motor activity as well as in heat production for the elevation of body temperature above ambient. Adrenergic stimulation of nonshivering thermogenesis may also be involved (e.g., Jansky and Jansky 2002).

However, it needs to be questioned whether the driving force for enhanced aerobic metabolism in mammalian and bird evolution came exclusively from progressively enhanced exercise levels. Early mammals and their ancestors were far from being long-distance endurance runners. In the beginning, mammalian ancestors were poikilotherms, due to small body size and lack of insulation (Ruben 1995). These forms derived from active therapsid reptiles that evolved during the Permian. Especially larger (i.e., less eurythermal) therapsids, however, did not survive the global cooling periods characterizing the Permian-Triassic or further Paleozoic and early Mesozoic mass extinction events (Stanley 1987). When mammals finally evolved from their small, cold eurythermal ancestors in the Late Triassic and Jurassic about 200 m.yr. ago (Rowe 1992), they were still small and under predatory pressure by once again larger therapsids and dinosaurs. Consequently, they remained small and were presumably active primarily during the cooler temperatures of the night (Ruben 1995, 1996). These small organisms were thus exposed to fast diurnal temperature oscillations on top of climate change. Being small, however, already implies an elevated metabolic rate per unit body mass (Schmidt-Nielsen 1984) and, accordingly, a high mitochondrial aerobic capacity (Hochachka et al. 1988), which causes enhanced production of metabolic heat and is associated with a larger degree of eurythermy (Figs. 5, 6). Extreme degrees of eurythermy as seen in extant mammalian hibernators may have contributed to the further maximization of metabolic rate (Fig. 6).

This scenario is in line with the general conclusion that mass extinction events driven by temperature oscillations likely selected small eurythermal species in similar ways in the terrestrial as in the marine realm. Since small eurytherms were the starting point for the next round of evolutionary speciation and radiation, this meant a selection and shift toward high activity life forms with high energy turnover (Fig. 4). Large oscillations in paleoclimates then appear as a prerequisite for the evolution of mammalian endothermy.

Such oscillations have in fact been observed. Long-term or seasonal climate oscillations became more pronounced in parallel to the rearrangements of continents, especially at high latitudes. First, climatic gradients and cold, glaciated poles developed when the supercontinent Pangaea covered all latitudes from North to South during the Permian. Second, dramatic climate oscillations between warm and cold periods caused or contributed to the wavelike progressive mass extinction events in marine and terrestrial, especially tropical environments in the late Permian as well as Triassic to Jurassic periods (Stanley 1987; Retallack et al. 2003). This global and long-term selective trigger provided by the oscillations between warm and cold periods (Knoll et al. 1996) was most likely complemented by the challenge to overcome excessive daily and seasonal temperature fluctuations in the arid climates of the supercontinent.

Furthermore, the scenario developed here strongly suggests that torpor or hibernation may have been early plesiomorphic strategies of small mammalian ancestors to save energy in response to the large oscillations in seasonal temperatures. They would thereby escape from excessive costs of cold adaptation, in similar ways as suggested previously for ectotherms. This conclusion is supported by the observation that torpor and hibernation are not triggered by food shortage but occur, for example, in echidnas, at reduced ambient temperatures, even with food around (Grigg and Beard 2000). In the absence of stress, energy reserves are thereby conserved. In endotherms in general, the cost of cold-adapted eurythermy is equivalent to the cost of euthermy, that is, the cost of maintaining a constantly high body temperature (Fig. 6).

In conclusion, the hypothesis that (cold) eurythermy was involved as a precondition in the evolution of high activity terrestrial vertebrates and finally endothermy is in line with the paleoclimate record and with the evolutionary patterns observed. The development of high activity levels and maximum endurable speeds sixfold to sevenfold higher in mammalian 


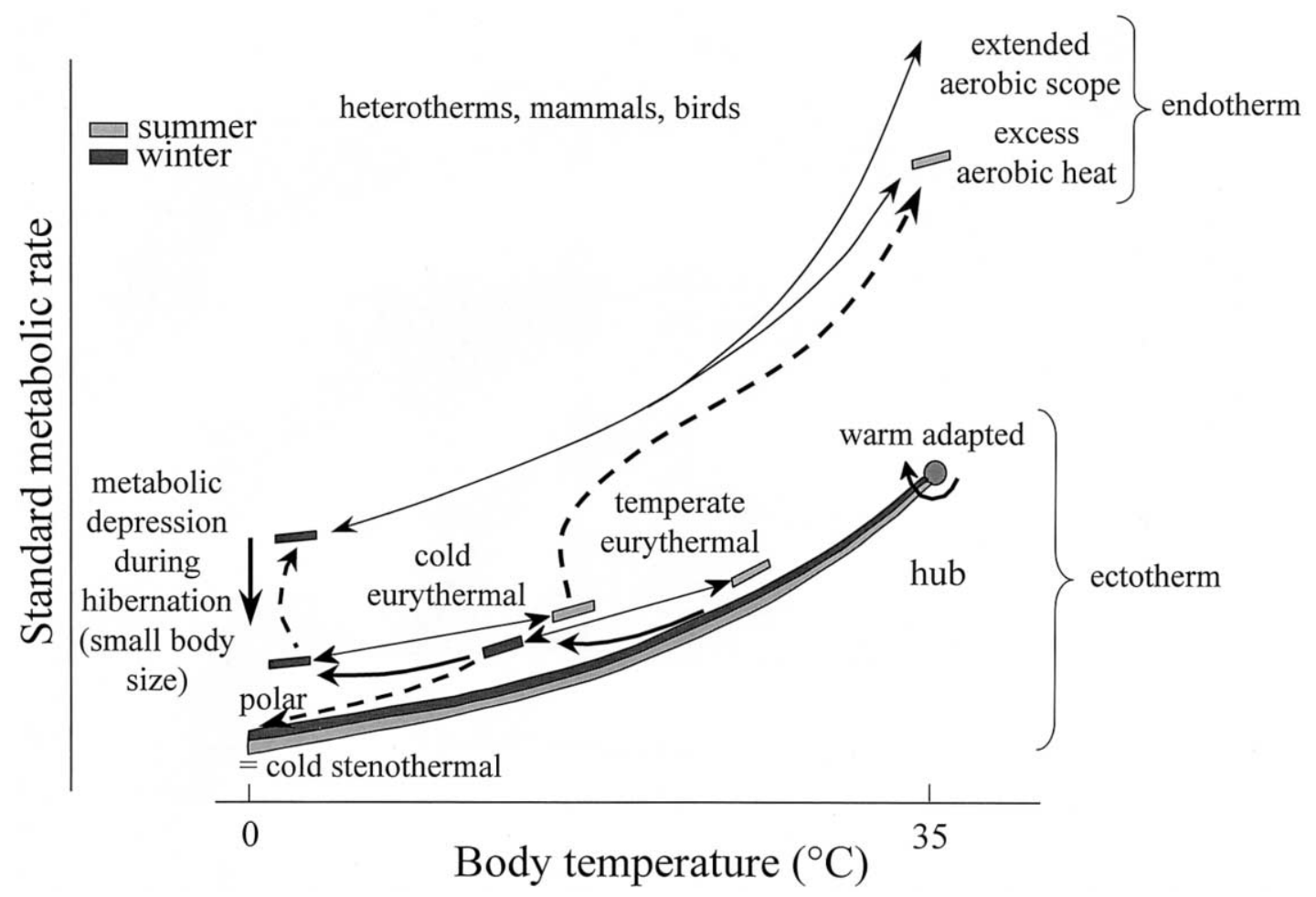

Figure 6. "Hub" of metabolic temperature adaptation during seasonal and permanent cold (modified after Pörtner et al. 2000), showing metabolic rate transitions for cold-stenothermal and cold-eurythermal ectotherms. Eurythermal cold adaptation causes the standard metabolic rate to increase in relation to the degree of ambient temperature fluctuations. This involves the cold compensation of mitochondrial aerobic capacity and proton leakage and the requirement to maintain function at both low and high temperatures. This trend is maximized, depending on the width of the thermal tolerance window and the requirement to maintain aerobic metabolism and scope at low body temperatures, at small body sizes, and during rapid temperature transitions. The qualitative model thereby extends to a depiction of the metabolic continuum between ectotherms and endotherms, based on high costs of cold adaptation in small protomammalian eurytherms (protoendotherms), which involve a permanently eurythermal tissue design. For the sake of clarity, metabolic rate differences between $0^{\circ}$ and $35^{\circ} \mathrm{C}$ are not to scale, especially for the endotherms (Heldmaier and Klingenspor 2000).

endotherms than in lizards (Bennett and Ruben 1979) then appears as a logical consequence of eurythermal tissue design (Pörtner 2002c). This line of thought is mutually exclusive with the hypothesis that endothermy arose from thermal inertia in large protomammalian ancestors and was conserved by increasing metabolic rate during a decrease in body size $(\mathrm{McNab}$ 1978, 1983).

\section{Scenario of Climate-Dependent Metabolic Evolution}

The following scenario of metabolic evolution in largely oscillating climates arises:

First, elevated resting metabolic rates typical for cold-adapted eurytherms allowed small protomammalian (and bird) ancestors to be permanently active in a wide range of temperatures including nighttime cold. This does not imply that they used aerobic scope extensively, but only that they were able to remain agile at low body temperatures at the expense of elevated SMRs. Owing to the relatively long half-life of mitochondria (about
1 wk; Hood 2001), acclimation to warmer daytime temperatures by reducing mitochondrial densities was not possible, resulting in a permanently high oxygen demand (favored by small body size). Extreme oscillations in body temperature result in a maximized level of energy expenditure (Fig. 6). On the one hand, this high level of oxygen demand had to be met by the selection for sophisticated ventilation and circulation systems among mammalian ancestors (Fig. 2). On the other hand, maximum heat output from high quantities of coldadapted mitochondria facilitated maintenance of elevated body temperatures.

Second, a precondition for maintained endothermy is insulation by lipids, fur, or feathers. In this context, a recent review of large-scale thermal adjustments in aquatic ectotherms suggested that cold exposure causes a shift to lipid accumulation and metabolism, a pattern most expressed in the permanent Antarctic cold. Moreover, this trend is more pronounced in active pelagic species with high mitochondrial densities than in benthic sessile species (Pörtner 2002c). Similar 
trends in terrestrial eurytherms, especially in their cold-exposed peripheral tissues, would favor the formation of insulating lipid layers, useful to reduce thermal conductance and to maintain elevated body temperatures.

Third, as a consequence of enhanced baseline and active energy expenditures, food requirements increased by the same factor (Bennett and Ruben 1979; Ruben 1995). A body core temperature independent of ambient values allowed for extended periods of activity and wide-roaming ranges as required to meet elevated food requirements. Constant body temperature also provided a thermal and energetic basis for beneficial incubation temperatures of the embryos and for extended parental care (Farmer 2000), required because of the small number of offspring. These considerations emphasize extended parental care as a secondary benefit and thereby eliminate the apparent contradiction between the two hypotheses, endothermy due to improved parental care versus aerobic scope for exercise as discussed recently (Angilletta and Sears 2003; Farmer 2003). In the light of present insight, both do not appear as prime driving forces for the evolution of endothermy but as secondary benefits. Permanent endothermy also evolved to maintain high reactivity during passive periods of hiding or rest, situations that requested sophisticated use of the reptilian thermostat. At small body size and in mammals only, endothermy was supported by a tissue specialized in heat production, which is brown adipose tissue with a maximum degree of mitochondrial uncoupling (Cannon et al. 2000).

Finally, the scenario drawn by Ruben (1995) is not only supported by the concept of extended ranges of cold-adapted eurythermy, but the forces behind the evolution of endothermy become fully comprehensible only in the light of this concept. The "high cost of eurythermy" hypothesis also complies with the conjecture that elevated metabolic rates did not evolve for high body temperatures and endothermy (Bennett and Ruben 1979; Ruben 1995), but, according to the rationale provided here, endothermy was a consequence of tissue eurythermy. Eurythermy (which encompasses tolerance to cold) arose as a "missing link" between ectothermy and endothermy because it provided the excess energy and aerobic scope required to evolve endothermy and associated benefits. Controlled endothermy then secured the availability of elevated aerobic scopes and agility at high body temperatures despite ambient fluctuations.

\section{Final Details: The Fossil Record and the Role of Atmospheric Oxygen Oscillations}

According to the symmorphosis principle, the transition to extreme eurythermy and then to endothermy could occur only under the precondition that the increase in oxygen demand was met by sophisticated ventilatory and circulatory systems, which should have evolved in eurythermal mammalian and bird ancestors (Fig. 2). As these were bound to be permanently active to cover the costs of eurythermy by adequate food intake, such systems could arise preferably in those vertebrates with improved locomotory structures for efficient long-term aerobic activity (Duncker 1991), that is, in therapsids. According to Ruben $(1995,1996)$ and Ruben et al. (2003), the presence of rudimentary anterolateral rostral ridges in the fossil record suggests that early respiratory turbinates, similar to those observed in all extant mammals and birds, were already present in large late Permian theriodont therapsids (250 m.yr.), wolflike inhabitants of subtropical regions, at a time $40-50 \mathrm{~m}$.yr. before the origin of the Mammalia. These structures support respiratory water recovery and protect the body from desiccation at high ventilation rates. Based on McNab (1978), Ruben (1995) postulated that these animals were at least inertial homeotherms in tropical to subtropical climates that did profit from elevated metabolic rates but did not yet use endogenous heat production for perfect thermoregulation. He later adopted the view that the turbinates qualify the therapsids as endotherms (Ruben et al. 2003). However, the turbinates may qualify these organisms as hypermetabolic but not necessarily and originally for the reason of endothermy. Large body sizes were eliminated during climate-driven mass extinction events such that the turbinates in small mammalian ancestors likely have arisen in response to excessive eurythermy and their high metabolic rate, but not in response to endothermy. Eurythermy as the "missing link" between ectothermy and endothermy would easily explain the origin of these patterns. Homeothermy in these therapsids may have secondarily arisen from the combined use of eurythermal tissues and elevated muscular activity at large body sizes, in similar ways as observed nowadays in tuna.

Similarly, the relative constancy of elevated body temperatures possibly existing among dinosaurs may not only be a consequence of large body masses and their thermal inertia (McNab 1978, 1983). Elevated degrees of cold-induced eurythermy may already have existed among dinosaurs and may have allowed cold-adapted representatives of this group to enter relatively cold subpolar environments (Rich et al. 2002). Eurythermy and the associated high oxygen demand at relatively large body sizes most likely have allowed dinosaurs to be more agile in colder climates than found in the extant, more sluggish reptilian species.

It should be noted, however, that the trends to maximize metabolic rates in endotherms reach beyond those observed in (extant) eurythermal ectotherms (Fig. 6). Such metabolic increments were possibly not only supported by the fact that small ("good") eurytherms survived mass extinction events (Fig. 4). In the context of oxygen-limited thermal tolerance, fluctuating atmospheric oxygen levels may also have played a role. First, largely elevated and then decreasing atmospheric oxygen levels may have been involved. During the Paleozoic, oxygen reached $35 \%$ in air between Carboniferous to Permian periods with a peak 300 m.yr. ago and decreased from these high values between 300 and 250 m.yr. (Fig. 4). Life forms with high energy turnover developing during the hyperoxic period 
(Graham et al. 1995) would have survived only by improving ventilatory and circulatory gas exchange. The progressive decrease in oxygen levels may have been relevant for the secondary selection of improved ventilatory and circulatory performance in hypermetabolic protomammalian therapsids.

In the Mesozoic, oxygen levels rose again and reached about $26 \%$ oxygen in air during mid-Jurassic to Cretaceous and Tertiary periods, 150 to 50 m.yr. ago. This period may have been relevant for the maximization of energy turnover and the evolution of endothermy in, once again, small ancestors of extant birds. These changes occurred later and possibly started from a more sophisticated ventilatory and circulatory design than in mammalian ancestors. The periods of enhanced oxygen availability might also have supported the evolution of enhanced aerobic metabolism during flight and associated exercise (Dudley 1998; Berner et al. 2000; Berner and Kothalova 2001). The decrease in oxygen levels after these later hyperoxia periods may again have contributed to the selection for progressively enhanced circulatory and ventilatory capacities. In the light of the general hypothesis that thermal tolerance is oxygen-limited in animal aerobes, the effects of concomitant fluctuations in temperature and atmospheric oxygen levels on the pathways of animal evolution warrant further investigation (Fig. 4).

\section{Endothermy in Water Breathers}

With the huge difference in oxygen levels, endothermy could develop earlier and more perfectly in air than in water. In scombroid fish like tuna and in lamnid shark, a current trend to develop endothermy appears to include pathways that are both similar and different from the patterns elaborated for the evolution of mammalian endothermy. In the water breathers, the use of rete mirabile or the conversion of muscle into heater organs contributes to produce and conserve body heat (Block 1991). However, elevated aerobic capacity owing to permanent eurythermy is likely involved, as reflected by the level of tissue heterothermy in the heater organs of tuna (Fudge et al. 1998). Ambient temperature oscillations may have served as evolutionary triggers and are both environmentally and behaviorally induced in these fish (Block 1991). This includes behavioral hyperthermia used to warm up in surface water layers and, secondly, vertical migrations into the cold deep after the migration of larger prey such as squid. In contrast to early mammalian endothermy, teleost and shark endothermy is supported by large body sizes and high performance levels. Thereby, heat loss is minimized, as discussed previously for the therapsids and dinosaurs (Fig. 7).

Why Be Warm? Trade-Offs in Setting the Right Body Temperature

As already indicated, another major question becomes accessible from acknowledging the principles of an oxygen-limited thermal tolerance in animals and also from acknowledging eurythermy in the cold as a primer for the evolution of endothermy. This question is why endotherms chose a permanently high body temperature close to upper thermal limits rather than at intermediate values. Optimization of physiological and biochemical function would have been possible at lower temperatures as well, evidenced by the complex pattern of cold adaptation in stenothermal Antarctic water breathers. Extending from the previous analysis and partly from the compilation by Cossins and Bowler (1987), benefits of selecting a high body temperature would include the following:

1. A body temperature above ambient is required for optimized temperature control and facilitated heat loss. Heat production by the metabolic machinery is severalfold higher in endotherms than in ectotherms and requires a large enough temperature gradient to facilitate heat loss. If endothermy developed in the relatively warm climates of the Mesozoic, it would have been difficult to defend a low body temperature against the prevailing high ambient values.

2. Specific heat of water is minimal at $35^{\circ} \mathrm{C}$, providing the best set point for fine control of temperature, that is, minimal heat that is required for warming. It should be emphasized, however, that bird temperatures reach much higher and close to Metazoan heat limits (see point 5).

3. Selection for high body temperatures is supported in air, not only because of reduced thermal buffering compared with water but also because more numerous thermal niches are usually accessible within shorter distances for air breathers than for water breathers. Behavioral changes are used to maximize activity and reactivity by choosing warm temperatures, for example, in the sun, or to escape daily or seasonal temperature extremes by hiding in the shade or even underground.

4. Optimal performance temperatures in active animals appear to be close to their upper thermal limits (for review, see Angilletta et al. 2002). Maximized power output also explains why the body temperature of some insects is brought to $35^{\circ} \mathrm{C}$ or even $40^{\circ} \mathrm{C}$ before and during flight. Temperature-dependent shapes of performance and growth curves are similar, which is in line with the dependence of both muscular performance and growth upon temperature-dependent maintenance of aerobic scope. The requirement to have full aerobic scope and maximum performance achievable under resting conditions would support a body temperature close to the upper pejus level, at which aerobic scope for performance is maximal (Fig. $5 B$; Pörtner et al. 2005). This occurs at the expense of elevated metabolic expenditure; however, the benefit will be faster reactivity, a larger scope for activity, and a higher power output than on the cold side of the tolerance window (Bennett 1990). Benefits are faster escape from predators, coverage of a larger roaming range and, thereby, enhanced accessibility of resources. Constantly high body temperatures alleviate some functional constraints imposed by cold temperatures and open opportunities 


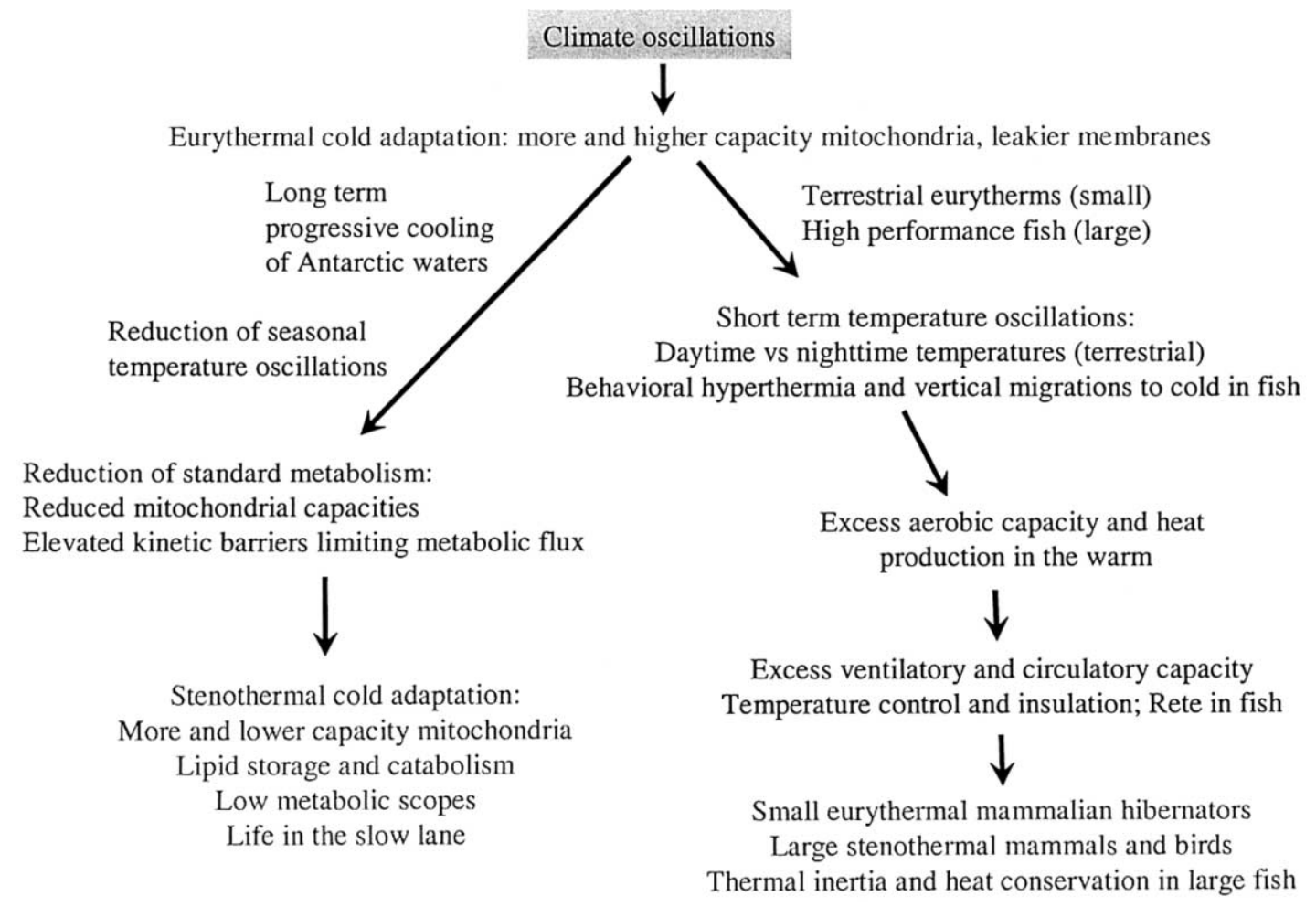

Figure 7. Contrasting pathways of the evolution of cold stenothermy (marine water breathers) versus warm endothermy (terrestrial air breathers; large high-performance fish, i.e., tuna), both starting from a situation characterized by eurythermal cold adaptation. Cold stenothermy seen in Antarctic marine animals results from a trend to minimize cold adaptation costs despite high mitochondrial densities. In this case, reduced levels of standard metabolism at maximized aerobic tissue design are supported by reduced capacities of mitochondrial respiration and, supposedly, by elevated kinetic barriers limiting metabolic flux (Pörtner et al. 1998, 2000). In contrast, exposure to short-term (especially daily) temperature oscillations causes maximized energy expenditure owing to cold-adapted aerobic capacities and minimized kinetic barriers and thereby forms the metabolic basis of excess heat production, as required for the maintenance of endothermy. Further preconditions for endothermy, that is, excess ventilatory and circulatory capacities and effective insulation, were met in highly evolved animal forms only. This scenario is supported by the biochemical and metabolic similarities observed in muscle tissue of cold-adapted eurytherms and of highperformance animals, for example, fish (Pörtner 2002c). The evolution of accessory heat production systems (like brown adipose tissue) is not considered crucial in these transitions.

to expand and use niches and high energy turnover life options otherwise not accessible to high-performance animal life.

5. Maximization of cellular to organismic performance by elevated body temperature depends on the level of ventilatory and circulatory capacity (Fig. 5) until close to the long-term upper limit of animal life, $45^{\circ} \mathrm{C}$. In general, and in accordance with the 30 -fold higher oxygen availability in air than in water, maximum sustained body temperatures are higher and approach metazoan limits more closely in air breathers than in water breathers. According to point 4, body temperatures are set at upper pejus temperatures and result from a trade-off between ambient oxygen levels, capacity of the gas exchange system and maximum aerobic activity, and power output levels in relation to baseline oxygen demand (aerobic scope). This conclusion supports an understanding of different body temperatures among mammals: in the more hypometabolic ("primitive") species (e.g., monotremata), lower ventilatory and circulatory capacities may explain their lower range of body temperatures starting at $32^{\circ} \mathrm{C}$ (Pörtner 2002a). Following this analysis, they have stopped half way (or returned to the slow lane) in a trade-off between setting body temperatures high and minimizing the level of energy turnover according to mode of life. In contrast, elevated whole organism aerobic capacity and energy demand are enforced by tissue heterothermy. This may support the shift of body core temperatures to higher values as observed in mammals at high Northern latitudes (Lovegrove 2003).

6. A comparison of gas exchange and circulatory systems would also explain why body temperatures are higher in birds than in mammals (Pörtner 2002a). In the mammalian lung, alveolar gaseous oxygen content remains far below that of inhalant air, since air moves in and out the same way such that incoming and outgoing oxygen-depleted air are always mixed in a pool system. In such a system, blood oxygen tensions $\left(\mathrm{Po}_{2}\right)$ 
remain below the $\mathrm{Po}_{2}$ of exhalant air. This design limitation (phylogenetic constraint) is eliminated in the bird lung, which operates at a continuous unidirectional flow of air. Gas exchange with a complex network of blood vessels occurs in a crosscurrent system that allows oxygenated arterial blood to reach a higher $\mathrm{Po}_{2}$ than exhaled air (Scheid and Piiper 1972; Schmidt-Nielsen 1997). As a consequence, the bird lung is two times more efficient than the mammalian lung in extracting oxygen from the air and in releasing $\mathrm{CO}_{2}$. On top of that, the circulatory system of birds is more powerful than that of mammalians (Ruben 1995). The malleability of the lung is lowest compared with other components of the oxygen delivery system (Jones 1998). Accordingly, the phylogenetic constraints associated with the design of the mammalian lung likely explain why the maximum sustained body temperatures of mammals are normally found between $37^{\circ}$ and $38^{\circ} \mathrm{C}$, whereas elevated oxygen availability allows for even higher temperatures above $40^{\circ} \mathrm{C}$ in birds without compromising aerobic scope. Consequently, a lesser degree of oxygen limitation at high temperatures would support the more active lifestyle of birds compared with mammals in hot terrestrial environments.

7. A crucial point not considered in point 4 arises from the treatment of metabolic trade-offs involved in cold-adapted eurytherms and stenotherms (Pörtner et al. 1998; Pörtner 2001, $2002 a, 2002 c$ ) and relates to temperature-dependent energy budgets. Cold stenotherms compensated for the cost of cold adaptation by reducing cellular and, as a consequence, systemic energy turnover including locomotion, to allow for the secondary minimization of mitochondrial energy demand (reflected in low proton leakage rates). Among Antarctic notothenioids as well as in a comparison of North Sea and Barents Sea cod, low standard metabolism was found to parallel enhanced growth rates. This apparent contradiction of low energy turnover (SMR) at maximized growth reflects enhanced cost efficiency in the permanent cold, despite maximized levels of aerobic machinery. Minimized SMR in the permanent Antarctic cold thus supports efficient growth and fecundity (Pörtner et al. 2001, 2005).

However, such a strategy to minimize metabolic costs and enhance growth performance was not accessible to protomammalian and protobird terrestrial eurytherms, which were under pressure to actively exploit low nighttime temperatures and to tolerate heat exposure during the day. In the heat, the high cost of oxygen delivery during warming and the high baseline idling of the cold-adapted machinery would become significant factors in the energy budget. By progressively improving ventilatory and circulatory capacities, they turned the apparent disadvantage inherent in high costs of eurythermy into a benefit. They used the excess mitochondrial ATP formation capacity available in the warm for maximizing not only agility but also growth. The associated formation of excess heat became available for thermoregulation. Maximized energy turnover thus compensates for the loss in growth performance, however, at the expense of elevated baseline costs. Among ectotherms, similar trends are found in extant coleoid cephalopods that maximized SMRs and even reach mammalian levels of growth rates (Lee 1994). At high resource availability, a maximization of energy turnover is thus an adequate strategy to escape from the trade-off between either maximized growth or a maximization of the capacity for muscular exercise.

Accordingly, the following conclusions integrate the various aspects of thermal adaptation in an optimality approach with respect to body temperature and thereby deepen the understanding of previously stated points 4-6:

Reaching less muscular performance despite maximized aerobic design characterizes the trade-offs and constraints involved in stenothermal cold adaptation required to support sufficient growth (Fig. 3B; Pörtner 2002c). In contrast, maximum availability of aerobic energy for maximized performance levels (covering both growth and exercise) requires high cost efficiency, which is reached at minimized densities of mitochondria but at their maximized ATP formation capacities. This leaves a maximum of cellular space for other functions including high concentrations of contractile proteins for muscular work (Fig. 2). Extrapolations to the warm end of the (eurythermal) activity spectrum immediately suggest that aerobic muscle with maximized aerobic power output at high cost efficiency is best designed close to upper metazoan heat limits. Starting from eurythermal cell design metabolic rates, efficiency and power output rise with increasing body temperatures as long as sufficient oxygen can be provided. Accordingly, the preferred or regulated body temperature in highly active ectotherms and endotherms is likely set to a value of maximized aerobic efficiency at payable costs of ventilation and circulation, as a tradeoff, that is, to the upper pejus temperature (Fig. $5 B$ ).

\section{Summary and Perspectives}

Although the chronological development of endothermy is not fully understood from the fossil record, the general picture arises that the evolution of mammalian and bird body temperatures is only one final step in the general context of the evolution of eurythermal life forms with high energy turnover. Oxygen-limited thermal tolerance windows in animals together with a role for eurythermy in the maximization of energy turnover and activity levels are indicative of a key role for climate oscillations, that is, temperature (and oxygen) oscillations, in the evolution of endothermy. The set of preconditions for the final step, the setting of controlled endothermy, involves (1) tolerance to extreme temperature fluctuations at low thermal buffering in air, (2) high ventilatory and circulatory capacity to profit from excess ambient oxygen availability, (3) a high degree of tissue eurythermy at small body size, and (4) the potential for perfect insulation. For a more detailed understanding of these relationships, the interactions between oscillating climate factors, patterns of biochemical adaptation, and 
their physiological whole organism consequences need to be investigated even further to come to a more thorough and quantitative understanding of the forces involved in climatedependent evolution. Along the way, it also needs to be addressed why, with excessive oxygen availability, maximum body temperatures tolerated permanently by animal aerobes do not likely exceed $45^{\circ}-47^{\circ} \mathrm{C}$.

\section{Acknowledgments}

I wish to thank Andy Clarke, Felix Mark, and Glenn Lurman for critically reading and commenting on the manuscript.

\section{Literature Cited}

Angilletta M.J., P.H. Niewiarowski, and C.A. Navas. 2002. The evolution of thermal physiology in ectotherms. J Therm Biol 27:249-268.

Angilletta M.J. and M.W. Sears. 2003. Is parental care the key to understanding endothermy in birds and mammals? Am Nat 162:821-825.

Azzam N.A., J.M. Hallenbeck, and B. Kachar. 2000. Membrane changes during hibernation. Nature 407:317-318.

Bambach R.K., A.H. Knoll, and J.J. Sepkowski, Jr. 2002. Anatomical and ecological constraints on Phanerozoic animal diversity in the marine realm. Proc Natl Acad Sci USA 99: 6845-6859.

Bennett A.F. 1990. Thermal dependence of locomotor capacity. Am J Physiol 259:R253-R258.

- 1991. The evolution of activity capacity. J Exp Biol 160:1-23.

Bennett A.F. and J.A. Ruben. 1979. Endothermy and activity in vertebrates. Science 206:649-654.

Berner R.A. and Z. Kothalova. 2001. Geocarb III: a revised model of atmospheric CO2 over Phanerozoic time. Am J Sci 301:182-204.

Berner R.A., S.T. Petsch, J.A. Lake, D.J. Beerling, B.N. Popp, R.S. Lane, E.A. Laws, et al. 2000. Isotope fractionation and atmospheric oxygen: implications for Phanerozoic $\mathrm{O}_{2}$ evolution. Science 287:1630-1633.

Blier P.U. and H. Lemieux. 2001. The impact of the thermal sensitivity of cytochrome $\mathrm{c}$ oxidase on the respiration of Arctic charr red muscle mitochondria. J Comp Physiol 171B: 247-253.

Block B.A. 1991. Endothermy in fish: thermogenesis, ecology and evolution. Pp. 269-311 in P.W. Hochachka and T.P. Mommsen, eds. Biochemistry and Molecular Biology of Fishes. Vol. 1. Elsevier Science, Amsterdam.

Bock C., A.M. Strijkstra, and H.O. Pörtner. 2002. MRI and ${ }^{31} \mathrm{P}$ NMR studies of brain metabolism in European ground squirrels during hibernation and arousal. Abstracts, International
Society for Magnetic Resonance in Medicine Annual Meeting, Hawaii.

Boyer B.B. and B.M. Barnes. 1999. Molecular and metabolic aspects of mammalian hibernation. BioScience 49:713-714.

Brand M.D., L.F. Chien, E.K. Ainscow, D.F. Rolfe, and R.K. Porter. 1994. The causes and functions of mitochondrial proton leak. Biochim Biophys Acta 1187:132-139.

Brand M.D., P. Couture, P. Else, K.W. Withers, and A.J. Hulbert. 1991. Evolution of energy metabolism: proton permeability of the inner membrane of liver mitochondria is greater in a mammal than in a reptile. Biochem J 275:81-86.

Brookes P.S., J.A. Buckingham, A.M. Tenreiro, A.J. Hulbert, and M.D. Brand. 1998. The proton permeability of the inner membrane of liver mitochondria from ectothermic and endothermic vertebrates and from obese rats: correlations with standard metabolic rate and phospholipid fatty acid composition. Comp Biochem Physiol 119B:325-334.

Buda C., I. Dey, N. Balogh, L.I. Horvath, K. Maderspach, M. Juhasz, Y.K. Yeo, and T. Farkas. 1994. Structural order of membranes and composition of phospholipids in fish brain cells during thermal acclimatization. Proc Natl Acad Sci USA 91:8234-8238.

Cannon B., V. Golozoubova, A. Matthias, K. Ohlson, A. Jacobsson, and J. Nedergaard. 2000. Is there life in the cold without UCP1? uncoupling proteins and thermoregulatory thermogenesis. Pp. 387-400 in G. Heldmaier and M. Klingenspor, eds. Life in the Cold. Springer, Berlin.

Carey C. and J.R. Hazel. 1989. Diurnal variation in membrane lipid composition of Sonoran desert teleosts. J Exp Biol 147: 375-391.

Chown S.L., A. Addo-Bediako, and K.J. Gaston. 2002. Physiological variation in insects: large-scale patterns and their implications. Comp Biochem Physiol 131B:587-602.

Chown S.L. and K.J. Gaston. 1999. Exploring links between physiology and ecology at macro-scales: the role of respiratory metabolism in insects. Biol Rev 74:87-120.

Cloud P. 1988. Oasis in Space, Earth History from the Beginning. Norton, New York.

Cloudsley-Thompson J.L. 2001. Thermal and water relations in desert beetles. Naturwissenschaften 88:447-460.

Cooper K.E. 2002. Molecular biology of thermoregulation: some historical perspectives on thermoregulation. J Appl Physiol 92:1717-1724.

Cossins A.R. and K. Bowler. 1987. Temperature Biology of Animals. Chapman \& Hall, London. 339 p.

Crowley T.J. and G.R. North. 1988. Abrupt climate change and extinction events in earth history. Science 240:996-1002.

Dudley R. 1998. Atmospheric oxygen, giant Palaeozoic insects and the evolution of aerial locomotor performance. J Exp Biol 201:1043-1050.

Duerr J.M. and S.S. Hillman. 1993. An analysis of $\mathrm{pH}$ tolerance and substrate preference of isolated skeletal muscle mito- 
chondria from Bufo marinus and Rana catesbeiana. Comp Biochem Physiol 106B:889-893.

Duncker H.R. 1991. Constructional and ecological prerequisites for the evolution of homeothermy. Pp. 331-357 in $\mathrm{N}$. Schmitt-Kittler and K. Vogel, eds. Constructional Morphology and Biomechanics. Springer, Berlin.

Else P.L. and A.J. Hulbert. 1987. Evolution of mammalian endothermic metabolism: "leaky" membranes as a source of heat. Am J Physiol 253:R1-R7.

Else P.L. and B.J. Wu. 1999. What role for membranes in determining the high sodium pump molecular activity of mammals compared to ectotherms? J Comp Physiol 169B:296302.

Farkas T., K. Kitajka, E. Fodor, I. Csengeri, E. Lahdes, Y.K. Yeo, Z. Krasznai, and J.E. Halver. 2000. Docosahexanoic acidcontaining phospholipid molecular species in brains of vertebrates. Proc Natl Acad Sci USA 97:6362-6366.

Farmer C.G. 2000. Parental care: the key to understanding endothermy and other convergent features in birds and mammals. Am Nat 155:326-334.

- 2003. Reproduction: the adaptive significance of endothermy. Am Nat 162:826-840.

Feder M.E. 1986. Effect of thermal acclimation on locomotor energetics and locomotor performance in a lungless salamander. J Exp Biol 121:271-283.

Frederich M. and H.O. Pörtner. 2000. Oxygen limitation of thermal tolerance defined by cardiac and ventilatory performance in the spider crab Maja squinado. Am J Physiol 279: R1531-R1538.

Frederich M., F.J. Sartoris, and H.O. Pörtner. 2001. Distribution patterns of decapod crustaceans in polar areas: a result of magnesium regulation? Pol Biol 24:719-723.

Fudge D.S., E.D. Stevens, and J.S. Ballantyne. 1998. No evidence for homeoviscous adaptation in a heterothermic tissue: tuna heat exchangers. Am J Physiol 275:R818-R823.

Gaston K.J. and S.L. Chown. 1999. Why Rapoport's rule does not generalise. Oikos 84:309-312.

Geiser F. 1998. Evolution of daily torpor and hibernation in birds and mammals: importance of body size. J Clin Exp Pharmacol Physiol 25:736-740.

Gilchrist G.W. 1995. Specialists and generalists in changing environments. I. Fitness landscapes of thermal sensitivity. Am Nat 146:252-270.

Gracey A.Y., J. Logue, P.E. Tiku, and A.R. Cossins. 1996. Adaptation of biological membranes to temperature: biophysical perspectives and molecular mechanisms. Pp. 1-21 in I.A. Johnston and A.F. Bennett, eds. Animals and Temperature: Phenotypic and Evolutionary Adaptation. Society for Experimental Biology Seminar Series 59. Cambridge University Press, Cambridge.

Graham J.B., R. Dudley, N.M. Aguilar, and C. Gans. 1995. Implications of the late Palaeozoic oxygen pulse for physiology and evolution. Nature 375:117-120.
Grigg G. and L. Beard. 2000. Hibernation by echidnas in mild climates: hints about the evolution of endothermy. Pp. 519 in G. Heldmaier and M. Klingenspor, eds. Life in the Cold. Springer, Berlin.

Guderley H. 1998. Temperature and growth rates as modulators of the metabolic capacities of fish muscle. Pp. 58-87 in H.O. Pörtner and R. Playle, eds. Cold Ocean Physiology. Society for Experimental Biology Seminar Series 66. Cambridge University Press, Cambridge.

Guderley H. and I.A. Johnston. 1996. Plasticity of fish muscle mitochondria with thermal acclimation. J Exp Biol 199:13111317.

Hardewig I., L.S. Peck, and H.O. Pörtner. 1999. Thermal sensitivity of mitochondrial function in the Antarctic Notothenioid, Lepidonotothen nudifrons. J Comp Physiol 169B:597604.

Hazel J.R. 1995. Thermal adaptation in biological membranes: is homeoviscous adaptation the explanation? Annu Rev Physiol 57:19-42.

Hazel J.R., S.J. McKinley, and E.E. Williams. 1992. Thermal adaptation in biological membranes: interacting effects of temperature and pH. J Comp Physiol 162B:593-601.

Heldmaier G. and M. Klingenspor, eds. 2000. Life in the Cold. 11th International Hibernation Symposium. Springer, Berlin. 546 pp.

Hochachka P.W. 1988. Channels and pumps: determinant of metabolic cold adaptation strategies. Comp Biochem Physiol 90B:515-519.

Hochachka P.W., B. Emmett, and R.K. Suarez. 1988. Limits and constraints on the scaling of oxidative and glycolytic enzymes. Can J Zool 66:1128-1138.

Hoffman P.F., A.J. Kaufman, G.P. Halverson, and D.P. Schrag. 1998. A Neoproterozoic snowball Earth. Science 281:13421346.

Hofmann G., B.A. Buckley, S. Airaksinen, J.E. Keen, and G.N. Somero. 2000. Heat-shock protein expression is absent in the Antarctic fish Trematomus bernacchii (family Nototheniidae). J Exp Biol 203:2331-2339.

Hood D.A. 2001. Contractile activity-induced mitochondrial biogenesis in skeletal muscle. J Appl Physiol 90:1137-1157.

Hoppeler H. and C.R. Taylor. 1992. Allometric scaling of muscle performance and metabolism: mammals. Pp. 143-151 in J.R. Sutton, G. Coates, and C.S. Houston, eds. Hypoxia and Mountain Medicine. Queen City, Burlington, Vt.

Huey R.B. and J.G. Kingsolver. 1993. Evolution of resistance to high temperature in ectotherms. Am Nat 142:S21-S46.

Hulbert A.J. and P.L. Else. 1999. Membranes as possible pacemakers of metabolism. J Theor Biol 199:257-274.

- 2000. Mechanisms underlying the cost of living in animals. Annu Rev Physiol 62:207-235.

Hulbert A.J., T. Rana, and P. Couture. 2002. The acyl composition of mammalian phospholipids: an allometric analysis. Comp Biochem Physiol 132B:515-527. 
Ivany L.C., W.P. Patterson, and K.C. Lohmann. 2000. Cooler winters as a possible cause of mass extinctions at the Eocene/ Oligocene boundary. Nature 407:887-890.

Jackman M.R. and W.T. Willis. 1996. Characteristics of mitochondria isolated from type I and type Iib skeletal muscle. Am J Physiol 270:C673-C678.

Jansky P. and L. Jansky. 2002. Sites and cellular mechanisms of human adrenergic thermogenesis: a review. J Therm Biol 27:269-277.

Johnston I.A., J. Calvo, H. Guderley, D. Fernandez, and L. Palmer. 1998. Latitudinal variation in the abundance and oxidative capacities of muscle mitochondria in perciform fishes. J Exp Biol 201:1-12.

Johnston I.A., H. Guderley, C.E. Franklin, T. Crockford, and C. Kamunde. 1994. Are mitochondria subject to evolutionary temperature adaptation? J Exp Biol 195:293-306.

Jones J.H. 1998. Optimization of the mammalian respiratory system: symmorphosis versus single species adaptation. Comp Biochem Physiol 120B:125-138.

Jourdan M.L., R. Hoo-Paris, and L.C.H. Wang. 1989. Characterization of hypothermia in a non-hibernator: the rat. Pp. 289-296 in A. Malan and B. Canguilhem, ed. Living in the Cold. 2. Colloque INSERM/John Libbey Eurotext, Montrouge.

Kawall H.G., J.J. Torres, B.D. Sidell, and G.N. Somero. 2002. Metabolic cold adaptation in Antarctic fishes: evidence from enzymatic activities of brain. Mar Biol 140:279-286.

King Y.T., C.-S. Lin, J.-H. Lin, and W.-C. Lee. 2002. Wholebody hyperthermia-induced thermotolerance is associated with the induction of heat shock protein 70 in mice. J Exp Biol 205:273-278.

Knoll A.H., R.K. Bambach, D.E. Canfield, and J.P. Grotzinger. 1996. Comparative earth history and Late Permian mass extinction. Science 273:452-456.

Koteja P., J.G. Swallow, P.A. Carter, and T. Garland. 2001. Maximum cold-induced food consumption in mice selected for high locomotor activity: implications for the evolution of endotherm energy budgets. J Exp Biol 204:1177-1190.

Krauss S., C.Y. Zhang, and B.B. Lowell. 2002. A significant portion of mitochondrial proton leak in intact thymocytes depends on expression of UCP2. Proc Natl Acad Sci USA 99:118-122.

Lee A.G., J.M. East, M.H. Hendersen, A.P. Starling, and J.Q.M. Warmerdam. 1994. Phospholipid requirements of the $\mathrm{Ca}^{2+}$ ATPase. Pp. 13-29 in A.R. Cossins, ed. Temperature Adaptation of Biological Membranes. Portland, London.

Lee P.G. 1994. Nutrition of cephalopods: fueling the system. Pp. 35-51 in H.O. Pörtner, R. O'Dor, and D.L. MacMillan, eds. Physiology of Cephalopod Molluscs: Lifestyle and Performance Adaptations. Gordon \& Breach, Basel.

Lindstedt S.L., T. McGothlin, E. Percy, and J. Pifer. 1998. Taskspecific design of skeletal muscle: balancing muscle structural composition. Comp Biochem Physiol 120B:35-40.
Lovegrove B.G. 2000. The zoogeography of mammalian basal metabolic rate. Am Nat 156:201-219.

. 2003. The influence of climate in the basal metabolic rate of small mammals: a slow-fast metabolic continuum. J Comp Physiol 173B:87-102.

Maloney S.K., A. Fuller, G. Mitchell, and D. Mitchell. 2001. Brain and arterial blood temperatures of free-ranging oryx (Oryx gazella). Pflueg Arch Eur J Physiol 443:437-445.

Mathieu-Costello O., P.J. Agey, E.S. Quintana, K. Rousey, L. $\mathrm{Wu}$, and M.H. Bernstein. 1998. Fiber capillarization and ultrastructure of pigeon pectoralis muscle after cold acclimation. J Exp Biol 201:3211-3220.

McNab B.K. 1978. The evolution of homeothermy in the phylogeny of mammals. Am Nat 112:1-21.

- 1983. Energetics, body size, and the limits to endothermy. J Zool (Lond) 199:1-29.

Mitchell D., S.K. Maloney, C. Jessen, H.P. Laburn, P.K. Kamerman, G. Mitchell, and A. Fuller. 2002. Adaptive heterothermy and selective brain cooling in arid-zone animals. Comp Biochem Physiol 131B:571-585.

Navas C.A. 2003. Herpetological diversity along Andean elevational gradients: links with physiological ecology and evolutionary physiology. Comp Biochem Physiol 133A:469-485.

Pehowich D.J. 1994. Lipid thermotropic phase behaviour in mammalian hibernation. Pp. 77-89 in A.R. Cossins, ed. Temperature Adaptation of Biological Membranes. Portland, London.

Pörtner H.O. 2001. Climate change and temperature dependent biogeography: oxygen limitation of thermal tolerance in animals. Naturwissenschaften 88:137-146.

- 2002a. Climate change and temperature dependent biogeography: systemic to molecular hierarchies of thermal tolerance in animals. Comp Biochem Physiol 132A:739-761.

- 2002b. Environmental and functional limits to muscular exercise and body size in marine invertebrate athletes. Comp Biochem Physiol 133A:303-321.

- 2002c. Physiological basis of temperature dependent biogeography: trade-offs in muscle design and performance in polar ectotherms. J Exp Biol 205:2217-2230.

Pörtner H.O., B. Berdal, R. Blust, O. Brix, A. Colosimo, B. De Wachter, A. Giuliani, et al. 2001. Climate effects on growth performance, fecundity and recruitment in marine fish: developing a hypothesis for cause and effect relationships in Atlantic cod (Gadus morhua) and common eelpout (Zoarces viviparus). Continental Shelf Res 21:1975-1997.

Pörtner H.O., I. Hardewig, and L.S. Peck. 1999. Mitochondrial function and critical temperature in the Antarctic bivalve, Laternula elliptica. Comp Biochem Physiol 124A:179-189.

Pörtner H.O., I. Hardewig, F.J. Sartoris, and P.L.M. van Dijk. 1998. Energetic aspects of cold adaptation; critical temperatures in metabolic, ionic and acid base regulation? Pp. 88120 in H.O. Pörtner and R. Playle, eds. Cold Ocean Physi- 
ology. Society for Experimental Biology Seminar Series 66. Cambridge University Press, Cambridge.

Pörtner H.O., M. Lucassen, and D. Storch. 2005. Metabolic biochemistry, an integrative view. In J.F. Steffensen and A.P. Farrell, eds. The Physiology of Polar Fishes, Fish Physiology 21 (in press).

Pörtner H.O. and F.J. Sartoris. 1999. Invasive studies of intracellular acid-base parameters: quantitative analyses during environmental and functional stress. Pp. 69-98 in S. Eggington, E.W. Taylor, and J.A. Raven, eds. Regulation of AcidBase Status in Animals and Plants. Society for Experimental Biology Seminar Series 68. Cambridge University Press, Cambridge.

Pörtner H.O., P. van Dijk, I. Hardewig, and A. Sommer. 2000. Levels of metabolic cold adaptation: trade-offs in eurythermal and stenothermal ectotherms. Pp. 109-122 in W. Davison and C.H. Williams, eds. Antarctic Ecosystems: Models for Wider Ecological Understanding. Caxton, Christchurch.

Pye V. 1973. Acute temperature change and the oxidation rates of ectotherm mitochondria. Pp. 83-96 in W. Wieser, ed. Effects of Temperature on Ectothermic Organisms. Springer, Berlin.

Raison J.K., E.J. McMurchie, J.S. Charnock, and R.A. Gibson. 1981. Differences in the thermal behaviour of myocardial membranes relative to hibernation. Comp Biochem Physiol 69B:169-174.

Rasmussen U.F. and H.N. Rasmussen. 2000. Human skeletal muscle mitochondrial capacity. Acta Physiol Scand 168:473480.

Retallack G.J., R.M.H. Smith, and P.D. Ward. 2003. Vertebrate extinction across Permian-Triassic boundary in Karoo Basin, South Africa. Geol Soc Am Bull 115:1113-1152.

Rich T.H., P. Vickers-Rich, and R.A. Gangloff. 2002. Polar dinosaurs. Science 295:979-980.

Rowe T. 1992. Phylogenetic systematics and the early history of mammals. Pp. 129-145 in F.S. Szalay and M.C. McKenna, ed. Mammalian Phylogeny. Springer, Berlin.

Roy K., D. Jablonski, J.W. Valentine, and G. Rosenberg. 1998. Marine latitudinal diversity gradients: tests of causal hypotheses. Proc Natl Acad Sci USA 95:3699-3702.

Ruben J. 1995. The evolution of endothermy in mammals and birds: from physiology to fossils. Annu Rev Physiol 57:6995.

. 1996. Evolution of endothermy in mammals, birds and their ancestors. Pp. 347-376 in I.A. Johnston and A.F. Bennett, eds. Animals and Temperature: Phenotypic and Evolutionary Adaptation. Society for Experimental Biology Seminar Series 59. Cambridge University Press, Cambridge.

Ruben J.A., T.D. Jones, and N.R. Geist. 2003. Respiratory and reproductive paleophysiology of dinosaurs and early birds. Physiol Biochem Zool 76:141-164.

Scheid P. and J. Piiper. 1972. Cross-current gas exchange in avian lungs: effects of reversed parabronchial air flow in ducks. Respir Physiol 16:304-312.

Schmidt-Nielsen K. 1984. Scaling: why is animal size so important? Cambridge University Press, Cambridge. . 1997. Animal Physiology: Adaptation and Environment. 5th ed. Cambridge University Press, Cambridge.

Scholander P.F., R. Hock, V. Walters, and L. Irving. 1950. Adaptation to cold in arctic and tropical mammals and birds in relation to body temperature, insulation, and basal metabolic rate. Biol Bull 99:259-271.

Schwerzmann K., H. Hoppeler, S.R. Kayar, and E.R. Weibel. 1989. Oxidative capacity of muscle and mitochondria: correlation of physiological, biochemical, and morphometric characteristics. Proc Natl Acad Sci USA 86:1583-1587.

Selkirk G.A. and T.M. McLellan. 2001. Influence of aerobic fitness and body fatness on tolerance to uncompensable heat stress. J Appl Physiol 91:2055-2063.

Sokolova I.M. and H.O. Pörtner. 2003. Metabolic plasticity and critical temperatures for aerobic scope in a eurythermal marine invertebrate (Littorina saxatilis, Gastropoda: Littorinidae) from different latitudes. J Exp Biol 206:195-207.

Sommer A.M. and H.O. Pörtner. 2002. Metabolic cold adaptation in the lugworm Arenicola marina: comparison of a North Sea and a White Sea population. Mar Ecol Prog Ser 240:171-182.

2004. Mitochondrial function in seasonal acclimatization versus latitudinal adaptation to cold in the lugworm Arenicola marina (L.) Physiol Biochem Zool 77:174-186.

Stanley S.M. 1987. Extinction. Scientific American, New York. Steen J.T., M.A. Vincent, and M.G. Clark. 1996. Resting muscle thermogenesis: novel mechanisms. Pp. 305-310 in F. Geiser, A.J. Hulbert, and S.C. Nicol, eds. Adaptations to Cold. 10th International Hibernation Symposium. University of New England Press, Armidale, Australia.

Storelli, C., R. Acierno, and M. Mafia. 1998. Membrane lipid and protein adaptations in Antarctic fish. Pp. 166-189 in H.O. Pörtner and R. Playle, eds. Cold Ocean Physiology. Society for Experimental Biology Seminar Series 66. Cambridge University Press, Cambridge.

St. Pierre J., P.-M. Charest, and H. Guderley. 1998. Relative contribution of quantitative and qualitative changes in mitochondria to metabolic compensation during seasonal acclimatisation of rainbow trout Oncorhynchus mykiss. J Exp Biol 201:2961-2970.

Suarez R.K. 1992. Oxygen and $\mathrm{Vo}_{2}$ max: are muscle mitochondria created equal? Pp. 136-142 in J.R. Sutton, G. Coates, and C.S. Houston, eds. Hypoxia and Mountain Medicine. Queen City, Burlington, Vt.

Suarez R.K., J.R.B. Lighton, G.S. Brown, and O. MathieuCostello. 1991. Mitochondrial respiration in hummingbird flight muscle. Proc Natl Acad Sci USA 88:4870-4873.

Tansey M.R. and T.D. Brock. 1972. The upper temperature limit 
for eukaryotic organisms. Proc Natl Acad Sci USA 69:24262428.

Taylor C.R. and E.R. Weibel. 1981. Design of the mammalian respiratory system. I. Problem and strategy. Respir Physiol 44:1-10.

Tiku P.E., A.Y. Gracey, A.I. Macartney, R.J. Beynon, and A.R. Cossins. 1996. Cold-induced expression of ${ }^{9} \Delta$-Desaturase in carp by transcriptional and posttranslational mechanisms. Science 271:815-818.

Tschischka K., D. Abele, and H.O. Pörtner. 2000. Mitochondrial oxyconformity and cold adaptation in the polychaete Nereis pelagica and the bivalve Arctica islandica from the Baltic and White Seas. J Exp Biol 203:3355-3368.

van den Thillart G. and G. de Bruin. 1981. Influence of environmental temperature on mitochondrial membranes. Biochim Biophys Acta 640:439-447.

Wikelski M., L. Spinney, W. Schelsky, A. Scheuerlein, and E. Gwinner. 2003. Slow pace of life in tropical sedentary birds: a common-garden experiment on four stonechat populations from different latitudes. Proc R Soc Lond 270:2383-2388.

Williams E.E. and J.R. Hazel. 1994. Thermal adaptation in fish membranes: temporal resolution of adaptive mechanisms. Pp. 91-106 in A.R. Cossins, ed. Temperature Adaptation of Biological Membranes. Portland, London.

Wodtke E. 1981. Temperature adaptation of mitochondrial membranes: the effects of acclimation temperature on the unsaturation of the main neutral and charged phospholipids in mitochondrial membranes of the carp (Cyprinus carpio L.). Biochim Biophys Acta 640:698-709.

Zakhartsev M., B. DeWachter, T. Johansen, H.O. Pörtner, and R. Blust. 2004a. Hsp70 is not a sensitive indicator of thermal limitation in the North Atlantic cod (Gadus morhua). J Fish Biol (in press).

Zakhartsev M., T. Johansen, H.O. Pörtner, and R. Blust. $2004 b$. Effects of temperature acclimation on lactate dehydrogenase of cod (Gadus morhua): genetic, kinetic and thermodynamic aspects. J Exp Biol 207:95-112. 